\title{
EFICIÊNCIAS DE DIFERENTES CULTURAS E HÍBRIDOS DE MILHO QUANTO A UTILIZAÇÃO DE FÓSFORO EM SOLOS DE CERRADO
}

\author{
Cristiano Fernandes
}

Dissertação apresentada à Escola Superior de Agricultura "Luiz de Queiroz", Universidade de São Paulo, para obtenção do título de Mestre em Agronomia, Área de Concentração: Solos e Nutrição de Plantas.

P I R A C I C A B A

Estado de São Paulo - Brasil

Julho -2001 


\title{
EFICIÊNCIAS DE DIFERENTES CULTURAS E HÍBRIDOS DE MILHO QUANTO A UTILIZAÇÃO DE FÓSFORO EM SOLOS DE CERRADO
}

\author{
Cristiano Fernandes \\ Engenheiro Agrônomo
}

Orientador: Prof. Dr. TAKASHI MURAOKA

\begin{abstract}
Dissertação apresentada à Escola Superior de Agricultura "Luiz de Queiroz", Universidade de São Paulo, para obtenção do título de Mestre em Agronomia, Área de Concentração: Solos e Nutrição de Plantas.
\end{abstract}

PIR A CIC A B A

Estado de São Paulo - Brasil

$$
\text { Julho }-2001
$$




\title{
Dados Internacionais de Catalogação na Publicação (CIP) \\ DIVISÃO DE BIBLIOTECA E DOCUMENTAÇÃO - Campus “Luiz de Queiroz"/USP
}

\author{
Fernandes, Cristiano \\ Eficiências de diferentes culturas e híbridos de milho quanto a utilização de \\ fósforo em solos de cerrado / Cristiano Fernandes. - - Piracicaba, 2001. \\ $51 \mathrm{p}$. \\ Dissertação (mestrado) - - Escola Superior de A gricultura Luiz de Q ueiroz, \\ 2001. \\ Bibliografia. \\ 1. A bsorção 2. A dubação fosfatada 3. Fixação 4. Fósforo 5. Milho híbrido 6. \\ Solo de cerrado I. Título
}

CDD 633.15

“Permitida a cópia total ou parcial deste documento, desde que citada a fonte - $O$ autor" 


\section{AGRADECIMENTOS}

Ao Prof. Dr. Takashi Muraoka pela orientação e amizade,

À FAPESP pela concessão da bolsa de mestrado,

À IAEA pelo apoio financeiro do projeto RC-BRA-10954,

Ao CNPq pela concessão da bolsa de produtividade de pesquisa,

Ao Edemar, Felipe e Anderson, amigos que contribuíram na elaboração dos experimentos e análises,

Aos funcionários, estagiários e colegas do Laboratório de Fertilidade do Solo do CENA/USP, pelo auxílio nas análises laboratoriais,

À minha família pelo incentivo e apoio, e

Aos meus amigos. 


\section{SUMÁRIO}

\begin{tabular}{|c|c|}
\hline \multirow{3}{*}{\multicolumn{2}{|c|}{ 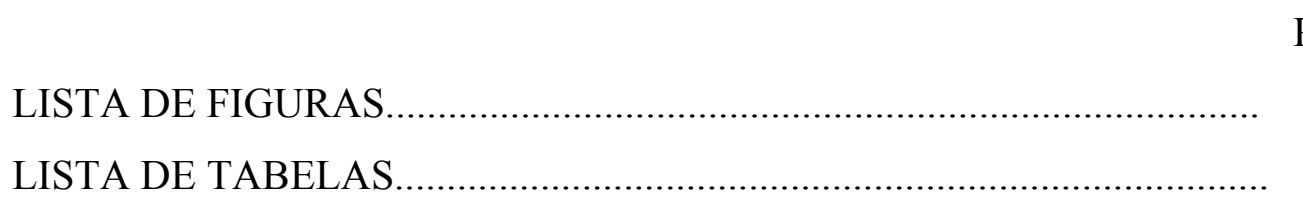 }} \\
\hline & \\
\hline & \\
\hline RESUMO & \\
\hline SUMMARY.. & \\
\hline 1 INTRODUÇÃO.......... & \\
\hline 2 REVISÃO DE LITERATURA... & \\
\hline 2.1 Cerrado... & \\
\hline 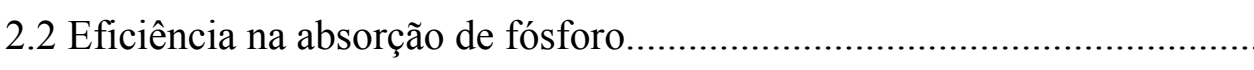 & \\
\hline 2.3 Variação genética do milho na eficiência na absorção de P...................... & \\
\hline 2.4 Métodos para avaliação da eficiência na absorção de P..... & \\
\hline 3 MATERIAL E MÉTODOS.................................................... & \\
\hline 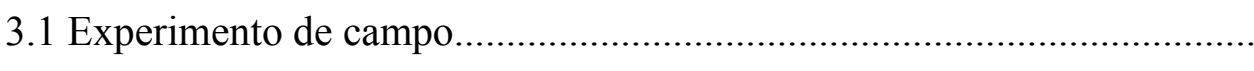 & \\
\hline 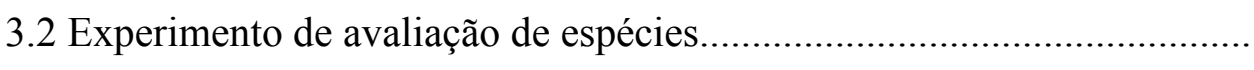 & \\
\hline 3.3 Experimento de avaliação de 30 híbridos de milho.... & \\
\hline 4 RESULTADOS E DISCUSSÃO......................... & \\
\hline 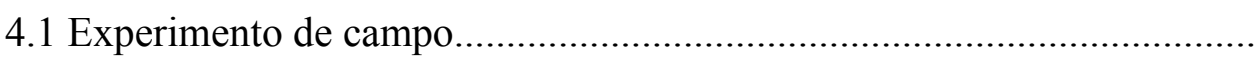 & \\
\hline 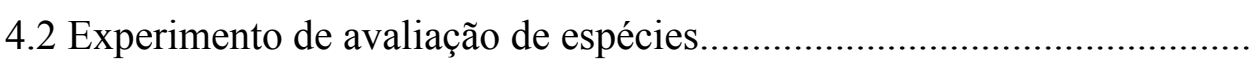 & \\
\hline 4.3 Experimento de avaliação de 30 híbridos de milho.......... & \\
\hline 5 CONCLUSÕES... & \\
\hline 6 ANEXOS.. & \\
\hline REFERÊNCIAS BIBLIOGRÁFICAS. & \\
\hline
\end{tabular}




\section{LISTA DE FIGURAS}

Página

1 Distribuição da precipitação durante o período de ago/99 a jul/00 na

Fazenda Alto Alegre - Planaltina-GO .....................................................

2 Classificação das culturas de acordo com a atividade específica ( $\left.\mathrm{CPM} \mu \mathrm{g}^{-1}\right)$.

3 Classificação dos híbridos como: ineficiente, medianamente eficiente e

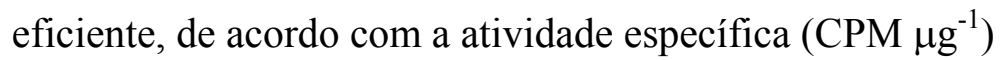




\section{LISTA DE TABELAS}

Página

1 Resultados da análise química de solo utilizados nos experimentos de campo

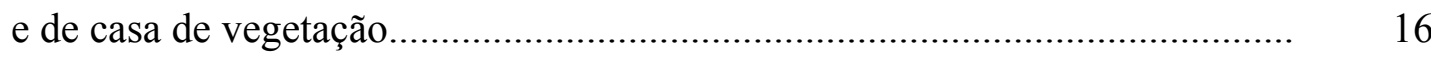

2 Espécies vegetais submetidas à comparação de eficiência na utilização de P..

3 Teores de $\mathrm{P}\left(\mathrm{g} \mathrm{kg}^{-1}\right)$ nas folhas e produtividade $\left(\mathrm{kg} \mathrm{ha}^{-1}\right)$ de híbridos de milho

4 Teores de P na parte aérea das plantas cultivadas em solo de cerrado..............

5 Produção de matéria seca (MS) e acúmulo de $\mathrm{P}$ na parte aérea por híbridos de milho e tremoço branco avaliados em solo de cerrado "cultivado"....

6 Atividade específica (S) e matéria seca (MS) da parte aérea de híbridos avaliados em solo de cerrado "natural" ....................................................... 38

1A Atividade específica de ${ }^{32} \mathrm{P}(\mathrm{S})$ das plantas cultivadas em solo de cerrado......

2A Atividade específica de ${ }^{32} \mathrm{P}(\mathrm{S})$ para o tremoço branco e híbridos de milho avaliados em solo de cerrado ("cultivado")................................................... 41

3A Classificação dos híbridos de milho quanto à época de maturação.................. 


\section{EFICIÊNCIAS DE DIFERENTES CULTURAS E HÍBRIDOS DE MILHO QUANTO A UTILIZAÇÃO DE FÓSFORO EM SOLOS DE CERRADO}

Autor: CRISTIANO FERNANDES

Orientador: PROF. DR. TAKASHI MURAOKA

\section{RESUMO}

Nas duas ultimas décadas, a região do cerrado tem sido uma das principais áreas de expansão agrícola no Brasil, apresentando características tanto favoráveis como limitantes à produção agrícola, principalmente quanto a disponibilidade de $\mathrm{P}$ no solo. $\mathrm{O}$ presente trabalho teve como objetivo avaliar os principais híbridos de milho recomendados para a região do cerrado quanto à capacidade de absorver o fósforo pouco disponível do solo e quanto às produtividades em dois solos da região de Planaltina de Goiás, um sob cultivo durante 20 anos e outro ainda sob vegetação natural. Foram previamente avaliadas 22 espécies vegetais (Crotalaria juncea, girassol, algodão, feijão, soja, tomate, tremoço branco, trigo, caupi, sorgo, milheto, aveia preta, triticale, arroz, milho, mucuna preta, amendoim, braquiária, stylosantes, eucalipto, guandu e cevada). Foram conduzidos três experimentos, sendo um em campo, no cerrado (Planaltina-GO), onde foram avaliadas as produções de matéria seca de parte aérea e de grãos, e acúmulo de $\mathrm{P}$ nas plantas de diversos híbridos de milho recomendadas para a região. Os outros 2 experimentos foram conduzidos no CENA/USP em casa de vegetação, onde se avaliou as espécies vegetais e os híbridos de milho quanto à eficiência na absorção e uso de $\mathrm{P}$ através da técnica da diluição isotópica de ${ }^{32} \mathrm{P}$. É possível atingir elevadas produtividades através da seleção de híbridos mais adaptados, podendo chegar a uma

produção de grãos acima de 9,0 t ha ${ }^{-1}$, como é o caso dos híbridos P30K75, P3021 e 
P30F33, enquanto outros apresentaram produtividade inferior a 7,4 $\mathrm{t}$ ha ${ }^{-1}$. Já quanto à eficiência na absorção de P do solo, os mais eficientes foram o ZN8420, P30F45, C813, ZN8471, DINA657, P30F33 e PX1339F apresentando baixa atividade específica. Entre estes híbridos, o P30F33 é uma boa opção de cultivo no cerrado. Quanto às espécies, o algodão, o eucalipto, o arroz e o tremoço branco foram os mais eficientes na absorção de fósforo, enquanto a crotalária, o caupi e a soja foram os menos eficientes, sendo mais dependentes de adubação fosfatada. 


\title{
EFFICIENCY OF DIFFERENT CROPS AND CORN HYBRIDS ON THE USE OF PHOSPHORUS IN CERRADO SOIL.
}

\author{
Author: CRISTIANO FERNANDES \\ Adviser: DR TAKASHI MURAOKA
}

\section{SUMMARY}

The Cerrado (Savannah) region has been one of main agriculture expansion area in Brasil, presenting favorable characteristics, but also limitations to crop production, mainly the low soil phophorus content and availability.

The objective of the work was to evaluate the mainly recommended maize hybrids for cerrado region on the ability to absorb poorly-available soil phosphorus and on the yield, in two soils of the Planaltina region of Goias, one cultivated for 20 years and another under natural vegetation. Preliminarly 22 plant species (Crotalaria juncea, sunflower, cotton, bean, soybean, tomato, white lupin, wheat, Caupi, Sorgum, millet, black oat, triticale, rice, maize, velvet bean, peanut, braquiaria, stylosantes, eucalyptus, pigeon pea and barley) were assessed. Three experiments were carried out, one of them in field, in cerrado region, where yield and $\mathrm{P}$ accumulation of grain and shoot were assessed. The other experiments were carried out in greenhouse at CENA/USP, where plant species and the corn hybrids were assessed for absorption and phosphorus use efficiency through the isotopic dilution technique of ${ }^{32} \mathrm{P}$. The results of field experiments showed that it is possible to obtain high yields through selected hybrids reaching yield higher than $9.0 \mathrm{tha}^{-1}$, as the case of hybrids P30K75, P3021 and P30F33, while another presented yield less than $7.4 \mathrm{t} \mathrm{ha}^{-1}$. The most efficient in phosphorus absorption were the ZN8420, P30F45, C813, ZN8471, DINA657, P30F33 and PX144F with low specific activity. Among these hybrids, the P30F33 seems to be a good option for cerrado. Comparing the crop species, the cotton, eucalyptus, rice and white lupin were more efficients in phosphorus absorption, while the crotalaria, caupi and soybean were less efficient consequently more dependents of phosphate fertilizers. 


\section{INTRODUÇÃO}

Para alcançar a demanda de alimentos no mundo no ano de 2025, o que seria, de acordo com a FAO, cerca de 4 bilhões de t de cereais em grãos, seria necessário pelo menos dobrar a produtividade atual das culturas (para 4,5 $\mathrm{t} \mathrm{ha}^{-1}$ ).

Tal aumento de produtividade, entretanto, seria somente possível nas regiões em desenvolvimento, porque as desenvolvidas, já alcançaram praticamente o limite no potencial produtivo da maioria das culturas.

No Brasil, uma das principais áreas de expansão de agricultura tem sido nas duas últimas décadas, a região do Cerrado, com cerca de 207 milhões de hectares. Aproximadamente 2/3 desta área, 136 milhões de hectares, é considerada apropriada para a produção de alimentos e pode ser incorporada ao processo produtivo (Macedo, 1996). Porém, são na maioria solos de baixa fertilidade e elevada acidez. Além disso, um dos principais fatores nutricionais limitantes da produção nestes solos, é a deficiência de fósforo, aliada à alta capacidade de fixação deste nutriente.

A produção brasileira de grãos, em 1990, foi de 56 milhões de t, quando na ocasião a produção desejada para o início do novo milênio visando suprir a necessidade da população estimada em 160 milhões, tinha sido de 140 milhões de t. Contudo, a produção estimada de grãos para este ano está ainda muito aquém daquele valor, 94,3 milhões de t, apresentando um crescimento de 13,5\% em relação à safra 1999/2000. Segundo a CONAB (Companhia Nacional de Abastecimento), a área brasileira cultivada com milho aumentou em 9,9\%, sendo que na região Centro Oeste este aumento foi de $29,9 \%$, em detrimento da queda de $4 \%$ na produtividade desta região. Provavelmente o único meio plausível que teria permitido alcançar este "gol" teria sido através da calagem e adubação, adequadamente e quantitativamente, já que o principal fator 
limitante em solos tropicais ácidos tem sido a deficiência em nutrientes além da acidez e suas conseqüências.

Assim, não raro agricultores tecnificados têm obtido altas produtividades, principalmente de milho e de soja, mas com elevada dose de adubação. Depara-se daí duas situações no Cerrado quanto ao fósforo: solos naturalmente pobres e outros com $\mathrm{P}$ total alto ou relativamente alto (na forma fixada) pela contínua adubação, mas baixa em sua disponibilidade.

Uma alternativa seria lançar mão de cultivares que tivessem maiores capacidades de absorver $\mathrm{P}$ menos disponível, resultando tanto em economia como também possibilitando melhor rendimento para agricultores com baixo capital de investimento.

Diversos trabalhos têm mostrado que diferentes cultivares de várias espécies apresentam características diferentes em relação à capacidade de absorção e utilização de nutrientes, assim como níveis variáveis de tolerância à toxidez por alumínio.

Um trabalho recente de Hocking et al. (1997) mostrou que a atividade específica de ${ }^{32} \mathrm{P}$ é um bom parâmetro para comparar espécies na absorção de fósforo, pois esta técnica é mais rápida que as convencionais acelerando os estudos.

Este trabalho tem como principal objetivo avaliar, usando a técnica da atividade específica de ${ }^{32} \mathrm{P}$, a eficiência dos híbridos de milho quanto à absorção de fósforo, tanto em condições de solo com baixa disponibilidade de fósforo como em solos adubados continuamente por vários anos.

As hipóteses de trabalho são: 1) Os híbridos de milho recomendados atualmente para o Cerrado variam quanto a sua capacidade em absorver $\mathrm{P}$ menos disponível do solo; 2) Os híbridos mais capazes terão o mesmo comportamento em solos continuamente adubados. 


\section{REVISÃO DE LITERATURA}

\subsection{Cerrado}

A região do cerrado brasileiro ocupa aproximadamente 207 milhões de ha, equivalente a 24,42\% do território nacional, dos quais 127 milhões de ha são considerados agricultáveis. Segundo Parentoni et al. (1999), atualmente 12 milhões de ha são responsáveis por $25 \%$ da produção nacional de soja, milho e arroz, $20 \%$ de café e 15\% de feijão. Cerca de 35 milhões de ha são destinados à produção animal gerando $40 \%$ da carne e $12 \%$ do leite produzidos no país.

Nesta região, os Latossolos somam aproximadamente $50 \%$ da área, os Podzólicos (15\%), as Areias Quartzosas (15\%), Litólicos e Cambissolos (10\%) e Plintossolos (6\%), ocupando mais de 95\% de sua superfície (Resende et al., 1996). A maioria destes solos são distróficos ou álicos, de baixa fertilidade e elevada acidez (Adámoli, et al., 1996).

A região associa características favoráveis com restritivas ao desenvolvimento agrícola. Dentre as favoráveis estão a topografia plana e textura dos solos que facilitam a mecanização; precipitação suficiente, porém má distribuída; temperaturas e luminosidade adequadas e boa drenagem dos solos; Entretanto, a maior restrição encontrada pelos agricultores consiste na associação da alta acidez (pH baixo e elevada saturação por alumínio) com a baixa fertilidade natural dos solos (Parentoni et al., 1999). Além disso, um dos principais fatores nutricionais limitantes da produção nestes solos, é a deficiência de fósforo aliada à alta capacidade de fixação deste nutriente. A maioria

dos solos estudados apresentam menos de $2 \mathrm{mg} \mathrm{dm}^{-3}$, valor muito abaixo dos níveis críticos usados na região (Lopes, 1984). Segundo Maroko et al. (1999), este problema 
acaba sendo intensificado com a produção intensiva e a aplicação insuficiente de fertilizantes para repor os nutrientes removidos com a colheita, levando a menores produtividades. $\mathrm{O}$ excesso de $\mathrm{Al}$ pode interferir na absorção e uso de $\mathrm{P}$ e outros nutrientes essenciais para as plantas (Lance \& Pearson, 1969; Foy, 1974, Castells et al., 1985).

Baligar et al. (1997), estudando 22 genótipos de milho cultivados em solo de cerrado, observaram que com o aumento da saturação por alumínio, tanto os genótipos menos eficientes e os mais eficientes no uso de macro e micronutrientes, apresentaram redução no acúmulo de massa seca das raízes e no crescimento das mesmas, levando a uma menor exploração do solo e conseqüentemente menor absorção de $\mathrm{P}$, uma vez que este é pouco móvel no solo.

Solos de cerrado, ácidos e com alta saturação por Al, apresentam problemas na solubilidade de seus compostos, principalmente nutrientes, que no caso do $\mathrm{P}$, com o abaixamento do $\mathrm{pH}$ ocorre diminuição em sua disponibilidade para as plantas. Outro ponto importante nestes solos é a CTC, ou seja, eles são ricos em sesquióxidos, gibsita e caulinita, cuja quantidade de cargas negativas é baixa resultando em baixa CTC, sendo que e em alguns casos, apresenta cargas positivas, aumentando a adsorção de ânions como o ortofosfato. Para minimizar estes problemas, práticas adequadas de manejo do solo, fertilizantes e plantas devem ser adotadas (Goedert et al., 1997).

O elevado grau de intemperização destes solos leva a altos teores de óxidos de Fe e Al, baixo pH, altos teores de aluminossilicatos (argilas silicatadas) e baixo teor de matéria orgânica. O fósforo é altamente fixado pelos óxidos de $\mathrm{Fe}$ e $\mathrm{Al}$ em pH ácido através de troca de ligantes $\left(\mathrm{OH}^{-}\right.$e $\left.\mathrm{OH}_{2}{ }^{+}\right)$por fosfato da solução do solo (adsorção específica) (Novais \& Smyth, 1999). Com o aumento do pH através da calagem, por exemplo, as cargas negativas aumentam, deslocando fosfato para a solução do solo. Argilas silicatadas apresentando $\mathrm{OH}^{-}$e/ou $\mathrm{OH}_{2}^{+}$em suas bordas também fixam $\mathrm{P}$ da solução. Quanto à matéria orgânica, além de fonte de $\mathrm{P}$ através de sua mineralização, também promove a formação de complexos fosfo-húmicos mais facilmente assimiláveis pelas plantas e mais fracamente retidos pelo solo, e reduz a fixação de $\mathrm{P}$ devido o 
revestimento das partículas de argila pelo húmus formando uma capa protetora que diminui o contato entre o fosfato e as partículas.

Neste sentido, diversos trabalhos têm sugerido alternativas para solução dos problemas de fertilidade que seriam, além de melhores técnicas de adubação e correção dos solos (Goedert et al., 1985), selecionar variedades de grãos e pastagens mais tolerantes ao alumínio e mais eficientes na absorção e utilização de fósforo e demais nutrientes (Furlani et al., 1985; Sawazaki \& Furlani, 1987; Macedo, 1996; Bahia Filho et al., 1997).

Plantas mais capazes de extrair o nutriente do solo, estratégias que minimizem a necessidade do nutriente decorrentes de diferenças no metabolismo, prevenindo assim a exaustão das reservas internas da planta e do solo resultando em maior eficiência no uso do nutriente na produção de biomassa, são características importantes para um efetivo crescimento e melhores rendimentos em solos com baixos teores de $\mathrm{P}$ como os de cerrado (Machado, 2000).

Assim, agricultores tecnificados do Cerrado vêm obtendo produtividades bastante altas de milho $\left(7 \mathrm{t} \mathrm{ha}^{-1}\right)$ e soja $\left(3 \mathrm{tha}^{-1}\right)$, graças principalmente a elevadas doses de fertilizantes e seleção de cultivares mais adaptadas à região, de acordo com o $\mathrm{Sr}$ Pagnussatt, agricultor na região do cerrado (Planaltina, GO). Muitos desses solos vem recebendo segundo ele, aplicações anuais, além de $\mathrm{N}$ e $\mathrm{K}$, de fósforo (90 $\mathrm{kg} \mathrm{P}_{2} \mathrm{O}_{5} / \mathrm{ha}$ ) ao longo dos últimos 20 anos. É de se esperar, portanto, que hoje esses solos contenham quantidades razoáveis de fósforo, que provavelmente está na forma pouco disponível para cultivares atualmente recomendadas, uma vez que ainda a capacidade de extração de P não tem sido a meta principal dos melhoristas para o milho, conforme se observa no livro Cultura do Milho (Bull \& Cantarella, 1993), no qual nem se cogita sobre o assunto.

A avaliação e seleção de cultivares de milho mais eficientes na absorção de fósforo, portanto, reveste-se de importância tanto para agricultores tecnificados como para os de baixo capital de investimento com o intuito de elevar sua produção e conseqüentemente, aumentar a quantidade de alimentos produzida no país. 


\subsection{Eficiência na Absorção de Fósforo}

Espécies vegetais apresentam diferenças quanto a sua capacidade em utilizar nutrientes e para o caso específico do fósforo diversos trabalhos tem comprovado este fato (Scott Russell et al., 1958, Rorison, 1968; Barrow, 1975).

Clarck \& Brown (1974) definem plantas eficientes em P como aquelas que acumulam maiores concentrações de fósforo quando elas são cultivadas a um certo nível deste nutriente. Loneragan \& Asher (1967) usam o termo eficiência de utilização de P, o qual definem como a quantidade de matéria seca produzida por unidade de $\mathrm{P}$ absorvido (ou recíproco da concentração). Essas duas definições são baseadas na quantidade de $\mathrm{P}$ absorvido e não permite a seleção para máxima produtividade de matéria seca em solo com baixo conteúdo de P disponível. Fox (1978), então, define uma planta eficiente como "aquela que produz uma grande quantidade de matéria seca por unidade ou tempo e área, desenvolvendo em um meio que tenha $\mathrm{P}$ disponível menos do que suficiente para máxima produtividade”. Segundo este autor a eficiência em P tem significado somente quando se comparam plantas sob mesmas condições quanto ao conteúdo de P no solo.

A capacidade de se desenvolver em solos com baixo teor de fósforo disponível tem sido atribuída a diversos fatores, incluindo diferenças na morfologia do sistema radicular e densidade dos pelos radiculares (Hocking et al., 1997). Assim, o tremoço branco (Lupinus albus) que é uma espécie bem adaptada aos solos ácidos deficientes em P (Gardner et al., 1983) forma raízes proteoides (aglomerado de radículas cobertas com denso emaranhado de pelos radiculares) que era considerado ser resposta a baixa disponibilidade de P (Marschner, 1995).

As principais características morfológicas do sistema radicular relacionadas à nutrição fosfatada, por configurarem um sistema eficiente na aquisição de $\mathrm{P}$, são comprimento e área de superfície das raízes, raio ou diâmetro radicular, relação de superfície (ou massa) radicular/massa de parte aérea e densidade de pelos radiculares (Machado, 2000).

As estratégias desenvolvidas pelas plantas para uma alta eficiência na absorção, segundo Föhse et al. (1988), diferem entre espécies. Algumas produzem 
grande sistema radicular, como o trigo, e outras apresentam uma alta taxa de absorção por unidade de comprimento radicular, como espinafre. Machado (2000) observou que plantas submetidas a um estresse de $\mathrm{P}$ apresentam uma inibição no crescimento total da planta e um aumento relativo no sistema radicular, significando que a redução no crescimento da parte aérea acontece antes da redução no crescimento das raízes, ou seja, como o sistema radicular está mais próximo do $\mathrm{P}$, seu crescimento ainda permanece por determinado período.

Rosolem \& Marcello (1998), estudando a influencia de níveis de Ca e P no crescimento radicular da soja cultivar IAC 17, observaram que houve formação de raízes mais finas e alongadas em resposta à baixa disponibilidade de $\mathrm{P}$, contradizendo $\mathrm{o}$ observado por Vilela e Anghinoni citados no trabalho. Teruel et al. (2001) constataram que plantas cultivadas em substrato carente em $\mathrm{P}$ apresentaram sistema radicular com maior número de raízes e mais profundos, sendo consideradas estratégias adaptativas das plantas à falta do nutriente.

Recentemente Keerthisinghe et al. (1997), no entanto, constataram que raízes proteoides aparecem também em tremoço branco a concentrações de P normais em solos agrícolas, não sendo essas formações por si só as grandes responsáveis pelo aproveitamento do fósforo. Na realidade, elas excretam grandes quantidades de ácidos cítricos que solubilizam o P "fixado" (Gardner et al., 1983; Keerthisinghe et al., 1997), aumentando a absorção de P pelas plantas. Da mesma forma, raízes de guandu (Cajanus cajan) excretam ácidos piscídico, malonico e oxalico, que parece ser o mecanismo pelo qual esta espécie é capaz de liberar o P dos fosfatos de alumínio e férrico (Otani et al., 1996).

Como comentado anteriormente, no estudo de Baligar et al. (1997), todos os genótipos estudados apresentaram redução no crescimento radicular e no acúmulo de massa seca de raízes, porém, os genótipos tolerantes ao Al têm grande potencial em aumentar o rendimento de matéria seca em níveis tóxicos de $\mathrm{Al}$, principalmente devido sua alta eficiência na utilização dos nutrientes absorvidos, principalmente o fósforo.

Em um experimento cujo objetivo foi estudar o acúmulo de matéria seca, N, P, $\mathrm{K}, \mathrm{Ca}, \mathrm{Mg}$ e $\mathrm{Zn}$, e a eficiência de conversão em grãos de três cultivares de milho, 
cultivados em um latossolo vermelho amarelo de Minas Gerais durante o invernoprimavera, Vasconcellos et al. (1998) observaram que não houve diferença com relação à produção de espigas e grãos entre os cultivares, assim como não houve diferença quanto à produção de grãos por unidade de $\mathrm{P}$ absorvido.

Colomb et al. (2000) conduziram um experimento durante 3 safras de milho, na França cujo objetivo foi estudar o efeito do nível de P no solo (de muito baixo a muito alto) sobre o desenvolvimento da área foliar e propriedades senescentes. Eles observaram que, em baixos níveis de $\mathrm{P}$, houve um atraso no aparecimento das folhas, redução na taxa de expansão das folhas, redução na área foliar máxima, que resultaram em diminuição na interceptação da luz solar, prejudicando deste modo o desempenho das plantas.

Muitas vezes, a aplicação de adubos fosfatados não resolve os problemas de deficiência de P, como observado por Hernandez \& Silveira (1998), avaliando os efeitos da saturação por bases, relação $\mathrm{Ca} / \mathrm{Mg}$ e doses de $\mathrm{P}$ na produção de massa seca pelo milho. Quando a relação Ca/Mg foi de 3/1 e 2/1, as doses de 100 e $200 \mathrm{mg} \mathrm{dm}^{-3}$ de $\mathrm{P}$ levaram a aumentos na produção de matéria seca enquanto as relações 4/1 e 5/1 resultaram em menores produções. A dose de $100 \mathrm{mg} \mathrm{dm}^{-3}$ de $\mathrm{P}$ foi a que apresentou melhor resposta em rendimento de matéria seca. Além disso, maiores acúmulos de $\mathrm{P}$ na parte aérea foram observados quando a relação $\mathrm{Ca} / \mathrm{Mg}$ foi de 3/1 e a saturação por bases foi de $70 \%$. Isso nos mostra que o equilíbrio entre os nutrientes do solo é fundamental para um bom rendimento, mesmo quando um determinado nutriente que está em falta é fornecido.

No caso da soja, a calagem não teve efeito significativo na produção de matéria seca, como observado por Rosolem \& Marcello (1998). Porém, quanto maior a saturação por bases do solo, maior a resposta às doses de $\mathrm{P}$ em termos de produção de matéria seca de parte aérea e total da planta, possivelmente devido à redução na adsorção específica e precipitação do $\mathrm{Al}^{3+}, \mathrm{Mn}^{2+} \mathrm{e} \mathrm{Fe}^{3+}$ responsáveis pela precipitação do $\mathrm{P}$ em pH abaixo de 7,0.

Avaliando híbridos simples de milho quanto à eficiência a $\mathrm{P}$ e a obtenção de novos híbridos a partir de linhagens mais eficientes, Parentoni et al. (1999) identificaram 
linhagens capazes de produzir híbridos altamente eficientes em fósforo e linhagens que só produzem híbridos superiores em ambientes sem estresse de $\mathrm{P}$.

Parentoni et al. (1999) também observaram num experimento utilizando 12 híbridos de milho em solução nutritiva sob 4 níveis de $\mathrm{P}$, que os dados obtidos em solução nutritiva utilizando seedlings são altamente influenciados pelo teor de $\mathrm{P}$ na semente. Isso nos faz questionar se em cultivo de plantas no solo pode sofrer este tipo de interferência.

Segundo Raghathama (1999), as mudanças adaptativas pelas plantas e resposta a limitação de $\mathrm{P}$ na rizosfera podem ainda ser de natureza fisiológica (aumento da translocação de P dentro da planta; secreção de fosfatases, alteração na respiração etc), bioquímica (ativação enzimática, ativação na produção de fosfatase, etc), como molecular (ativação de genes como RNAses, transportadores de fosfatos, PEP carboxilase, etc).

Diferenças genotípicas na atividade da fosfatase e respostas em função do grau de deficiência de $\mathrm{P}$ são esperadas, uma vez que estas enzimas são produtos diretos dos genes e pelas plantas diferirem significativamente em seus requerimentos nutricionais (Machado 2000). Besford ${ }^{1}$, citado por Machado (2000), verificou boa relação entre hábitos de crescimento, requerimento nutricional e atividade da fosfatase ácida em folhas de cevada, abóbora, milho, aveia, arroz, tomate e trigo. Quando submetidas a baixo nível de fósforo, todas as espécies apresentaram aumento na atividade da enzima, sendo mais pronunciado em abóbora e tomate, enquanto que nos cereais os aumentos foram mais singelos.

Mudanças no $\mathrm{pH}$ da rizosfera de plantas, liberação de ácidos orgânicos pelas raízes e desenvolvimento de associações simbióticas entre micorrizas e raízes também podem interferir na absorção de $\mathrm{P}$ do solo, sendo que variações genéticas nas plantas estão relacionadas a estes mecanismos (Santos et al., 1996; Keltjens, 1997; Machado, 2000).

\footnotetext{
${ }^{1}$ BESFORD, R.T. Phosphorus nutrition and acid phosphatase activity in the leaves of seven plant species. Journal of the Science and Food and Agriculture, v.30, p.281-5, 1979.
} 
Moura et al. (1999) avaliaram 10 linhagens de pimentão quanto à eficiência nutricional em relação ao fósforo, assim como a dose mais adequada para estudos de comparação entre genótipos obtendo como resultados variabilidade genética em todas as doses aplicadas ao solo, sendo que a maior variabilidade ocorreu na dose de $250 \mathrm{mg}$ de $\mathrm{P} / \mathrm{kg}$ de solo, considerando esta dose como a mais adequada para avaliação de genótipos de pimentão quanto à eficiência a P, como levantado por Furlani et al., citados por Moura et al. (1999), associada à produção de matéria seca da parte aérea.

\subsection{Variação Genética do Milho na Eficiência na Absorção de P}

Segundo Marschner (1995), nutrição mineral de plantas é controlada geneticamente. Em outras palavras, há diferença nutricional entre cultivares ou linhagens dentro de uma espécie. Diversos são os trabalhos demonstrando este fato para o fósforo (Clark \& Brown, 1974; Lindgreen et al., 1977, Furlani et al., 1985; Schjorring \& Nielsen, 1987; Graham et al., 1992; Hocking, 1997).

Em milho, a preocupação sobre diferenças varietais na absorção de fósforo não é recente. Assim, Smith, citado por Fox (1978), constatou que algumas linhagens de milho apresentavam desenvolvimento duas ou três vezes mais rápido em baixa concentração de $\mathrm{P}$ do que outras. Baker et al. (1970) observaram existir grandes diferenças geneticamente controladas na acumulação de $\mathrm{P}$ pelos híbridos de milho, mas que esse acúmulo não estava relacionado com a habilidade da planta em extrair P de solo com baixo nível. Concluíram que o teor de $\mathrm{P}$ em seedlings de milho podia ser usado para diagnostico de disponibilidade de $\mathrm{P}$ no solo. Schenk \& Barber (1980) também constataram a presença de diferenças nas propriedades morfológicas e fisiológicas das raízes relacionadas à absorção de $\mathrm{P}$ em três genótipos de milho avaliados em campo, indicando a possibilidade de seleção de genótipos mais eficientes na aquisição de fósforo.

Anghinoni et al. (1989) avaliaram os parâmetros morfológicos de raiz e cinéticos de absorção de P por quatro genótipos de milho: Save 342, Agroceres 28, Pionner PX301 e Caçador, e observaram que o cultivar Caçador, devido seus dados de 
Vmax (taxa máxima de absorção) e Cmin (concentração do nutriente na solução abaixo da qual a absorção cessa), apresenta características relevantes em relação à eficiência na absorção de P. Já o híbrido PX301, devido seu alto Cmin, se mostrou pouco eficiente, evidenciando a possibilidade de seleção de genótipos mais adaptados a condições de baixa disponibilidade de nutrientes no solo. Neste mesmo trabalho, foram selecionados genótipos de trigo e arroz mais eficientes na absorção de P, como o Nobre e o Bluebelle, respectivamente. Quando se avaliou espécies vegetais, a aveia forrageira e a canola apresentaram baixo Km (concentração do nutriente na solução onde ocorre a metade do Vmax) e Cmin indicativos de maior eficiência na absorção de $\mathrm{P}$ sob condições de estresse.

Nielsen \& Barber (1978) observaram haver diferenças na cinética de absorção de $\mathrm{P}$ em doze linhagens de milho, da ordem de 1,8 a 3,3 vezes no peso e comprimento de raízes por unidade da parte aérea, e no influxo máximo de P. Comparando os parâmetros de raízes e de absorção de $\mathrm{P}$ de híbridos cultivados em solução nutritiva com os cultivares no campo, concluíra que a absorção de $\mathrm{P}$ estava sob controle genético e que a heterose havia ocorrido nos cruzamentos.

Alves et al. (1998), também estudando a absorção e a translocação do fósforo em híbridos de milho submetidos a duas doses de $\mathrm{P}$, observaram que na menor dose de $\mathrm{P}$ houve aumento no influxo líquido de $\mathrm{P}$, diminuição no peso e conteúdo de $\mathrm{P}$ no exudato xilemático, e diminuição na porcentagem de $\mathrm{P}$ translocado da raiz para a parte aérea.

Schenk \& Barber (1979) observaram que a área superficial de raízes por unidade de peso da parte aérea variou entre genótipos, em condições de baixo nível de $\mathrm{P}$, mas não em condições de alto nível de $\mathrm{P}$.

Parentoni et al. (1999) observaram que genótipos ineficientes em P quando cultivados em solução nutritiva com estresse de P não apresentaram diferenças em nível de sistema radicular, enquanto que os considerados eficientes, aumentaram o peso e o comprimento das raízes após o estresse de P. Estes aumentos no comprimento foram de $55 \%$ para os híbridos simples, $61 \%$ para o duplo e $112 \%$ para o triplo. 
Kummerová $^{2}$, citado por Machado (2000), estudou o efeito da deficiência de P na atividade da fosfatase ácida em folhas de milho, observando que a deficiência primeiramente foi refletida na atividade enzimática da folha mais velha, aumentando sucessivamente na segunda e terceira folha com o agravamento da deficiência. Em outro trabalho, Kummerová \& Buresová ${ }^{3}$, citados por Machado (2000) comentam, através do estudo de dois genótipos de milho, que a atividade de fosfatases pode ser considerada como um dos muitos mecanismos desenvolvidos pelas plantas para manter seu metabolismo normal mesmo em condições deficitárias de fósforo disponível.

No Brasil, como os problemas de acidez e alumínio são mais limitantes para o desenvolvimento das culturas, os trabalhos de seleção de cultivares têm sido direcionados para esses aspectos (Galvão \& Silva, 1978; Oliveira et al., 1983; Furlani et al., 1986), sendo poucos trabalhos sobre o assunto eficiência em absorção de P. Provavelmente única cultura que tem merecido bastante atenção é a de feijão, pelo pesquisador do CIAT M. Thung durante o período que esteve no CNPAF-EMBRAPA (Thung, 1990). Para o caso do milho, conhece-se o trabalho de Furlani et al. (1985), que compararam em solução nutritiva, 40 linhagens de milho quanto à eficiência de absorção de P, selecionando 11 como ineficientes, 20 medianamente e 9 eficientes, com base na produção de matéria seca de parte aérea e raízes e absorção de $\mathrm{P}$ como características de avaliação. Furlani \& Furlani (1991), concluíram que a eficiência em fósforo e tolerância a alumínio, em milho e arroz, são características independentes.

Entre os trabalhos relacionados à eficiência na absorção e uso do fósforo pelo milho está o de Machado et al. (1999), no qual foram conduzidos dois experimentos, um em casa de vegetação avaliando 18 genótipos de milho submetidos a duas doses de P (10 e $100 \mathrm{mg} \mathrm{kg}^{-1}$ de solo), e outro em campo avaliando sete genótipos sob doses crescentes de P. Quanto à produção de matéria seca da parte aérea, não houve diferença significativa entre os genótipos estudados, exceto para o híbrido XL 560 cuja produção

\footnotetext{
2 KUMMEROVÁ, M. Acid phosphatase activity in maize leaves as related to their evolution and phosphorus deficiency. Biologia Plantarum, v.28, n.5, p.391-5, 1986.

3 KUMMEROVÁ, M.; BURESOVÁ, I. The effect of exogenous phosphate deficiency on the activity of acid phosphatase of the root of two maize genotypes. Biologia Plantarum, v.32, n.1, p.1-7, 1990.
} 
foi significativamente menor. O conteúdo de $\mathrm{P}$ na parte aérea diferiu dentro de cada dose aplicada, sendo que na menor o híbrido P 6875 apresentou maior acumulação, porém não diferindo significativamente da maioria dos genótipos. Já na maior dose, o maior acúmulo de P foi observado nas variedades BR 107, Catetão e Palha Roxa.

Quanto à eficiência na utilização do $\mathrm{P}$, estes mesmos autores observaram que de um modo geral, a maior eficiência ocorreu nas doses mais elevadas de adubação fosfatada, sendo que apenas o híbrido P 6875 não foi influenciado pelas doses de $\mathrm{P}$, apresentando a menor demanda de $\mathrm{P}$ para atingir a produtividade máxima de grãos $\mathrm{e}$ maior produção de grãos por unidade de P aplicada. Na menor dose, foi o híbrido P 6875 que se mostrou mais eficiente em relação aos demais. Mesmo sendo mais eficiente no uso do P em baixas doses, este híbrido foi superado, em termos de produção de grãos, pela variedade Caiano de Sobrália na ausência de adubação fosfatada. Isso vem denotar que o híbrido P 6875 e a variedade Caiano de Sobrália estão mais adaptados a condições de carência de P no solo e conseqüentemente mais indicados para condições do cerrado, em termos de eficiência a P.

Numerosos são os trabalhos que mostram variações adaptativas em culturas quando submetidas a estresses nutricionais, as quais justificam a importância de trabalhos que visam selecionar genótipos mais eficientes e produtivos em sistemas de cultivo onde os teores de nutrientes disponíveis no solo não são suficientes (Baker et al. 1970; Nielsen \& Barber 1978; Schenk \& Barber 1979; Furlani et al. 1985; Thung, 1990; Machado et al. 1999; Parentoni et al. 1999).

\subsection{Métodos para Avaliação da Eficiência na Absorção de $\mathbf{P}$}

Os parâmetros normalmente usados para avaliação da eficiência na absorção de P pelas espécies ou cultivares dentro das espécies são: taxa de absorção de P (TAP) taxas relativas de crescimento da planta (TRCP) (Asher \& Loneragan, 1967; Clarkson, 1967 e Nassery, 1970). O TAP é definido como quantidade de P absorvido pela planta por unidade de peso da raiz por unidade de tempo (por ex.: $\mu \mathrm{gP} / \mathrm{g}$.dia); TTR (taxa de translocação e redistribuição) é a quantidade de $\mathrm{P}$ translocado para parte aérea por 
unidade de peso de raízes por unidade de tempo (ex: $\mu \mathrm{gP} / \mathrm{g}$.dia) e a TRCP pode ser definido como o aumento de matéria seca por unidade de tempo (ex: g/g.dia).

A maioria dos trabalhos citados anteriormente basearam-se em um ou outro desses parâmetros.

Recentemente Hocking et al. (1997) compararam a habilidade de diferentes espécies vegetais em acessar P do solo pouco disponível, através da técnica de diluição isotópica de ${ }^{32} \mathrm{P}$. A vantagem dessa técnica é a possibilidade de medir diretamente as diferenças entre plantas na capacidade de absorção de $\mathrm{P}$ menos disponível, não dependendo diretamente de nenhum dos parâmetros TAP, TTP ou TRCP. Concluíram que o tremoço branco realmente é a espécie mais eficiente, quando foi comparado com canola, tremoço azul, guandu, soja, girassol e trigo, sendo a soja a pior.

Segundo Di et al. (2000), a técnica de diluição isotópica tem ganhado adeptos na determinação das transformações de nutrientes no sistema solo-planta, baseando-se na abundancia natural do isótopo em estudo ou na atividade específica (S) quando são utilizados radioisótopos, que é o caso do ${ }^{32} \mathrm{P}$.

Algumas plantas podem desenvolver estratégias que levam a maiores rendimentos em condições limitantes de fertilidade do solo, decorrentes de diferenças metabólicas, na absorção e na capacidade de extrair o nutriente pouco disponível do solo, principalmente no caso do P. Daí a necessidade de avaliar quanto do nutriente presente na planta veio do solo e quanto veio do fertilizante, o que pode ser feito através da técnica de Diluição Isotópica de ${ }^{32} \mathrm{P}$, como feito por Hocking et al. (1997).

A técnica da diluição isotópica de ${ }^{32} \mathrm{P}$ será utilizada neste trabalho para a avaliação dos híbridos e das culturas quanto à eficiência na absorção de $\mathrm{P}$ de solos de cerrado, calculando-se a atividade específica (S) para cada um.

Atividade específica de ${ }^{32} \mathrm{P}$ é calculada pela relação entre CPM (contagens por minuto) e a quantidade total de $\mathrm{P}$ na planta ( $\mu \mathrm{g}$ de $\mathrm{P}$ ), cuja unidade será CPM $\mu \mathrm{g}^{-1}$, indicando quanto do fósforo presente na planta é proveniente do fertilizante (marcado com ${ }^{32} \mathrm{P}$ ) e por diferença, quanto é proveniente do solo. Plantas com maior $\mathrm{S}$ possuem mais $\mathrm{P}$ proveniente do fertilizante e menos do solo, sendo menos eficientes em absorver o nutriente do solo. 


\section{MATERIAL E MÉTODOS}

\subsection{Experimento de Campo}

O experimento foi instalado na Fazenda Alto Alegre, município de Planaltina de Goiás - GO, região do cerrado brasileiro, constituindo de uma parceria entre a referida fazenda e empresas produtoras de sementes de milho cujo objetivo era selecionar os híbridos mais produtivos para a região, sendo então incorporado neste trabalho para assim auxiliar na escolha dos híbridos para o experimento de casa de vegetação. A localização geográfica da área experimental é: $15^{\circ} 14^{\prime}$ de latitude Sul e $47^{\circ}$ 42 ' de latitude oeste, estando a $826 \mathrm{~m}$ acima do nível do mar. O solo é classificado como Latossolo Vermelho Amarelo distrófico de textura argilosa, cujas características químicas são apresentadas na tabela 1 .

O clima da região, segundo a classificação de Köppen, é do tipo Aw, apresentando clima tropical com duas estações bem definidas: seca e chuvosa. A duração do período seco é de quatro a cinco meses, sendo a temperatura média anual de $20^{\circ} \mathrm{C}$ e precipitação média anual de 1200 a $1800 \mathrm{~mm}$ (Adámoli et al, 1986), sendo que a distribuição da precipitação medida na área experimental é apresentada na figura 1.

O solo onde se instalou o experimento vem sendo cultivado durante 20 anos, onde recebe constantes adubações recomendadas para as culturas, sob sistema de plantio direto e rotação milho/soja/pastagem. O plantio ocorreu em 01 de novembro de 1999, recebendo adubação de plantio de $300 \mathrm{~kg} \mathrm{ha}^{-1}$ da fórmula 09-30-15 (composição: sulfato de amônio, cloreto de potássio e MAP), e aos 35 dias, adubação de cobertura com N e K, utilizando $310 \mathrm{~kg} \mathrm{ha}^{-1}$ da fórmula 30-00-15 (sulfato de amônio e cloreto de potássio). 
As plantas utilizadas foram 27 híbridos de milho, sendo 26 comerciais recomendados para a região e um resultante do cruzamento de dois outros híbridos comerciais (CRUZ) feito na própria fazenda. Foram feitas análises químicas de folha, planta inteira e grãos, alem da avaliação da produtividade de grãos e de massa seca. Os híbridos avaliados foram: P3072, P30R07, P30F33, P3081, P30F88, P3071, P30F80, P3041, P30F45, P30K75, PX1268Z, PX1318J, P3021, PX1318H, AG6018, AG6690, ZN8474, ZN8550, ZN8420, C909, C813, C929, C333B, C747, DINA766, TORK e CRUZ.

Tabela 1: Resultados da análise química de solo utilizados nos experimentos de campo e de casa de vegetação.

\begin{tabular}{lcc}
\hline \multicolumn{1}{c}{ Solo } & Natural* & Cultivado* \\
\hline $\mathrm{MO}\left(\mathrm{g} \mathrm{kg}^{-1}\right)$ & 22,55 & 22,55 \\
$\mathrm{~S}(\mathrm{mg} \mathrm{dm}$ & \\
P resina $(\mathrm{mg} \mathrm{dm}$ & -3 & 2,50 \\
$\mathrm{pH}\left(\mathrm{H}_{2} \mathrm{O}\right)$ & 5,40 & 26,70 \\
$\mathrm{pH}\left(\mathrm{CaCl}_{2}\right)$ & 5,02 & 6,11 \\
$\mathrm{~K}\left(\mathrm{mmol}_{\mathrm{c}} \mathrm{dm}^{-3}\right)$ & 4,12 & 5,32 \\
$\mathrm{Ca}\left(\mathrm{mmol}_{\mathrm{c}} \mathrm{dm}^{-3}\right)$ & 1,49 & 23,85 \\
$\mathrm{Mg}\left(\mathrm{mmol}_{\mathrm{c}} \mathrm{dm}^{-3}\right)$ & 1,51 & 9,61 \\
$\mathrm{H}+\mathrm{Al}\left(\mathrm{mmol}_{\mathrm{c}} \mathrm{dm}^{-3}\right)$ & 65,81 & 26,05 \\
$\mathrm{SB}\left(\mathrm{mmol}_{\mathrm{c}} \mathrm{dm}^{-3}\right)$ & 4,60 & 35,26 \\
$\mathrm{CTC}\left(\mathrm{mmol}_{\mathrm{c}} \mathrm{dm}^{-3}\right)$ & 70,41 & 61,31 \\
$\mathrm{~V} \%$ & 6,50 & 57,50 \\
\hline
\end{tabular}

* Solo natural está sob vegetação original de cerrado; Solo cultivado vem sendo utilizado para cultivo nos últimos 20 anos.

O delineamento experimental adotado foi em blocos casualizados, com quatro repetições para cada híbrido totalizando 108 parcelas. Cada parcela foi composta de cinco linhas com espaçamento de $0,90 \mathrm{~m}$ entre linhas e $200 \mathrm{~m}$ de comprimento com uma área total de $900 \mathrm{~m}^{2}$. 
Foram coletadas amostras das folhas logo abaixo da espiga na época de pleno florescimento, as quais foram secas em estufa a $60^{\circ} \mathrm{C}$ por 48 horas, moídas e analisadas quanto aos teores de macro (N, P, K, Ca, Mg e S) e micronutrientes (Fe, Mn, Cu e Zn), segundo metodologia descrita por Sarruge \& Haag (1974).

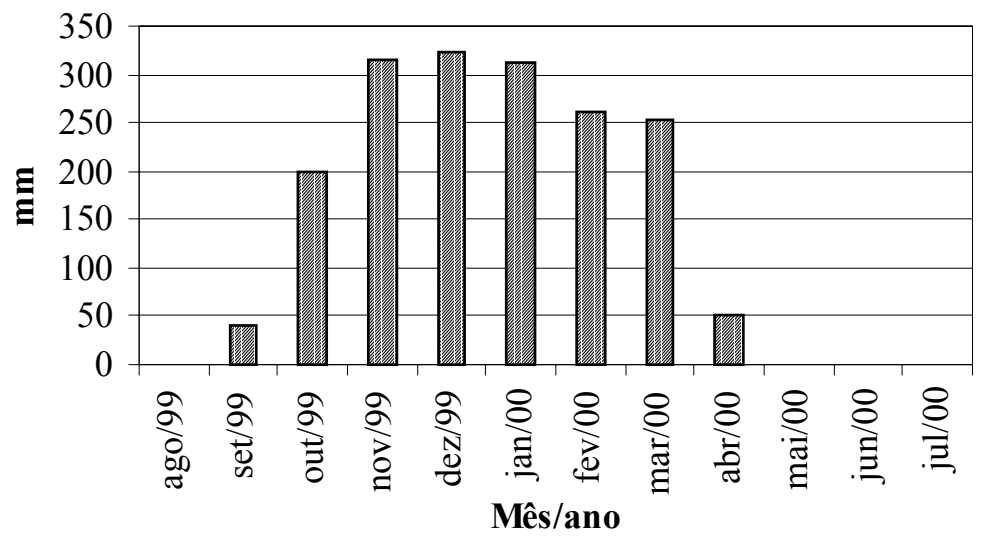

Figura 1: Distribuição da precipitação durante o período de ago/99 a jul/00 na Fazenda Alto Alegre - Planaltina-GO

$\mathrm{Na}$ época da maturação fisiológica foram coletadas três plantas por parcela, cujos grãos foram separados e pesados para determinar os teores de macro $(\mathrm{N}, \mathrm{P}, \mathrm{K}, \mathrm{Ca}$, $\mathrm{Mg}$ e S) e micronutrientes ( $\mathrm{Fe}, \mathrm{Mn}, \mathrm{Cu}$ e $\mathrm{Zn}$ ) na parte aérea, segundo metodologia descrita por Sarruge \& Haag (1974). As plantas foram trituradas juntamente com as palhas das espigas e sabugo. Desta massa foi retirada uma alíquota que passou pelo mesmo processo das folhas até a determinação dos nutrientes. Os grãos foram pesados (massa verde), secos em estufa a $60^{\circ} \mathrm{C}$ por 48 horas e pesados novamente (massa seca), determinando assim umidade dos mesmos. Em seguida eles também seguiram o mesmo processo das folhas. A produção de massa seca por hectare foi determinada mediante $o$ calculo da massa seca das três plantas multiplicada pelo numero de plantas por hectare. Os grãos produzidos em cada parcela foram colhidos e pesados, sendo calculada a produtividade em $\mathrm{kg} \mathrm{ha}^{-1}$. Os resultados foram analisados estatisticamente pelo método de Tukey a $5 \%$. 


\subsection{Experimento de avaliação de espécies}

Este experimento foi conduzido em casa de vegetação no Centro de Energia Nuclear na Agricultura - CENA/USP, com o objetivo de avaliar espécies de plantas cultivadas quanto à eficiência na utilização de $\mathrm{P}$ em solo com baixa disponibilidade deste nutriente.

O solo utilizado foi coletado na Fazenda Alto Alegre em Planaltina de Goiás sob vegetação de cerrado não perturbada pela ação do homem (natural) num único local uniforme na camada de $0-20 \mathrm{~cm}$, cujas características químicas estão na tabela 1 . Cada vaso, revestido com saco plástico recebeu $1,5 \mathrm{~kg}$ de solo peneirado.

Quanto às espécies de plantas, foram comparadas 22 espécies diferentes, entre elas, culturas anuais de grande importância, algumas utilizadas em adubação verde e uma espécie arbórea, o eucalipto. A relação completa é apresentada na tabela 2, com os nomes comuns, nome científico e cultivar de cada espécie.

Cada vaso foi revestido com saco plástico de parede grossa para evitar vazamentos, recebendo posteriormente $1,5 \mathrm{~kg}$ de terra peneirada, num total de 66 vasos. Em seguida foram preparados 66 copinhos plásticos com $20 \mathrm{~g}$ de areia fina os quais receberam $10 \mathrm{MBq}$ (megabecquerel) de ${ }^{32} \mathrm{P}$. Após um repouso de 48 horas, a areia foi homogeneizada e cada copinho foi aplicado em um vaso com solo para marca-lo, juntamente com 1,0 g/vaso da mistura de $\mathrm{CaO}$ e $\mathrm{MgO}$ na proporção de 3:1 com a finalidade de corrigir o $\mathrm{pH}$ do solo, além de $300 \mathrm{mg}$ de $\mathrm{P} /$ vaso cuja fonte foi fosfato de Patos para elevar o nível de $\mathrm{P}$ do solo. $\mathrm{O}$ solo foi homogeneizado, irrigado com 0,5 L/vaso de água destilada e deixado em repouso por três dias até o plantio. 
Tabela 2: Espécies vegetais submetidas à comparação de eficiência na utilização de $\mathrm{P}$.

\begin{tabular}{ccc}
\hline Nome comum & Nome científico & Cultivar/híbrido \\
\hline Crotalária juncea & Crotalaria juncea L & IAC-KR1 \\
Girassol & Helianthus annus L & IAC Uruguai \\
Algodão & Gossypium hirsutum $\mathrm{L}$ & IAC 280 \\
Feijão & Phaseolus vulgaris $\mathrm{L}$ & Carioca bico de ouro \\
Soja & Glycine javanica & Celeste \\
Tomate & Lycopersicum esculentum Mill & Sta Cruz Kada Gigante \\
Tremoço branco & Lupinus albus & Comum \\
Trigo & Triticum aestivum L & BRS 120 \\
Caupi & Vignia unguiculata L Walp & Branquinho \\
Sorgo & Sorghum bicolor L Moench & AG 2002 \\
Milheto & Pennisetum glaucum & BN-2 \\
Aveia preta & Avena strigosa Schieb & Comum \\
Triticale & Tritico secale & IAC-2 \\
Arroz & Oryza sativa L & IAC 165 \\
Milho & Zea mays & P30F33 \\
Mucuna preta & Mucuna aterrina & Comum \\
Amendoim & Arachis hipogacea L & Tatu \\
Braquiária & Brachiaria brizantha & Brizanta \\
Stylosantes & Stylosanthes guianensis & Mineirão \\
Eucalipto & Eucaliptus grandis & IAC Fava Larga \\
Guandu & Cajanus cajan L & BR 2 \\
Cevada & Hordeum vulgare L & \\
\hline & &
\end{tabular}

Após o repouso os vasos foram abertos e cada um recebeu cinco sementes, sendo três repetições cada cultura. $\mathrm{O}$ eucalipto, tomate, braquiária e stylosantes foram pré-germinados em areia, sendo transplantados para os vasos no mesmo dia em que as demais espécies foram semeadas. Os vasos foram novamente irrigados com $40 \mathrm{~mL}$ de água destilada. Durante todo o experimento a umidade do solo foi controlada mantendose a massa de $1,9 \mathrm{~kg} /$ vaso.

Aos 6 dias após o plantio foi realizada uma adubação com $10 \mathrm{mg}$ de P/vaso (DAP), e aos 8 dias após o plantio foi feito um desbaste, mantendo 2 plantas por vaso e adubação com $50 \mathrm{mg} \mathrm{kg}^{-1}$ de $\mathrm{N}$ e K e S (sulfato de amônio + cloreto de potássio). A adubação com micronutrientes (B, Cu, Mn, $\mathrm{Zn}$ e Mo) foi realizada aos 12 dias através da 
aplicação de $10 \mathrm{~mL} /$ vaso da solução de Johanson (Epstein, 1975). Aos 18 dias, foi feita uma adubação de cobertura a base de $\mathrm{N}$ e K, na mesma dose aplicada na primeira.

$\mathrm{O}$ corte das plantas foi feito aos 32 dias, as quais foram secas em estufa a $60^{\circ} \mathrm{C}$ por 48 horas e pesadas para determinação da massa seca. Em seguida foram moídas a analisadas quanto ao teor de $\mathrm{P}$ na parte aérea pelo método de Colorimetria do Metavanadato, além da contagem do ${ }^{32} \mathrm{P}(\mathrm{CPM})$ por cintilação líquida.

As contagens de ${ }^{32} \mathrm{P}$ foram feitas em Contador de Cintilação em Meio Líquido, o qual detecta a radiação emitida pelo radioisótopo $\left({ }^{32} \mathrm{P}\right)$ em um determinado período de tempo, obtendo desta forma as contagens por minuto (CPM) para cada amostra.

Com os valores de $\mathrm{P}$ e contagem, foi calculada a Atividade Específica para cada cultura para avaliação da eficiência na absorção do P dos solos, sendo que quanto menor a atividade específica, maior a eficiência na absorção de $\mathrm{P}$ do solo e vice-versa.

Os resultados foram analisados estatisticamente pelo método de Tukey a 5\%. $\mathrm{O}$ delineamento experimental usado foi o inteiramente casualizado.

\subsection{Experimento de avaliação de 30 híbridos de milho}

Este ensaio teve como objetivo estudar 30 híbridos comerciais de milho recomendados para a região do cerrado quanto à eficiência na utilização de fósforo, conduzido em casa de vegetação no CENA/USP. Os híbridos selecionados são: P3071, P30F33, P3081, P30F80, P3027, P3041, P30F45, P3021, P30F88, P30K75, PX1409K, PX1379F, PX1339F, PX1359G, DINA657, DINA766, C813, C909, C747, C333B, ZN8550, ZN8410, ZN8452, ZN8420, ZN8471, AG6018, AG9090, AG7575, DKB911 e TORK, cuja classificação quanto à época de maturação é apresentada na tabela $3 \mathrm{~A}$.

Para a instalação do experimento utilizaram-se 93 vasos para cada tipo de solo, ou seja, solo sob cultivo há 20 anos e solo sob vegetação natural. Os dois tipos de solo foram coletados na Fazenda Alto Alegre, na camada de $0-20 \mathrm{~cm}$. Cada vaso, revestido com saco plástico foi preenchido com $1,5 \mathrm{~kg}$ de terra. Aplicou-se o material marcado, 6,0 MBq (megabecquerel) de ${ }^{32} \mathrm{P}$ em copinhos com $20 \mathrm{~g}$ de areia cada um. Após a secagem, homogeneizou-se a areia e adicionou-se o conteúdo de cada copinho em um 
vaso. Homogeneizou-se a terra com a areia e retornou-se ao vaso novamente. Em seguida, irrigaram-se os vasos com $0,5 \mathrm{~L} /$ vaso de água destilada e deixou-se em repouso durante 18 dias com os sacos fechados.

Após o período de repouso, abriram-se os sacos e plantaram-se três sementes por vaso. No total semearam-se 30 híbridos comerciais de milho e o tremoço branco utilizado como planta padrão, sendo três repetições cada um. A irrigação foi feita quando necessário mantendo a massa dos vasos em 1,9 kg. Passados oito dias do plantio, foi realizado um desbaste deixando duas plantas por vaso. Aos 12 dias após o plantio foi realizada uma adubação com $100 \mathrm{mg} \mathrm{kg}^{-1}$ de $\mathrm{N}$ (sulfato de amônio), $100 \mathrm{mg} \mathrm{kg}^{-1}$ de K $(\mathrm{KCl}), \mathrm{S}$, e com micronutrientes $(\mathrm{B}, \mathrm{Cu}, \mathrm{Mn}, \mathrm{Zn}$ e $\mathrm{Mo}$ ) através da aplicação de 10 $\mathrm{mL} /$ vaso da solução de Johanson (Epstein, 1975), além da aplicação de $\mathrm{Ca}\left(\mathrm{CaCl}_{2}\right)$ e $\mathrm{Mg}$ $\left(\mathrm{Mg}\left(\mathrm{NO}_{3}\right)_{2}\right)$.

Este ensaio foi conduzido durante 34 dias já que as plantas dos vasos com solo natural paralisaram seu crescimento devido à baixa fertilidade do solo. Passado este período, as plantas foram cortadas e submetidas à secagem em estufa a $60^{\circ} \mathrm{C}$ durante 48 horas. Depois de secas, elas foram pesadas para determinação de massa seca e analisadas quimicamente quanto ao teor de P na parte aérea, segundo Sarruge \& Haag (1974), e contagem do ${ }^{32} \mathrm{P}$ por cintilação líquida, como no experimento anterior. Com os valores de $\mathrm{P}$ e contagem, foi calculada a Atividade Específica (S) para cada híbrido para avaliação da eficiência na absorção do P dos solos. Quanto menor a atividade específica, maior a eficiência na absorção de P do solo e vice-versa.

Os resultados foram analisados estatisticamente pelo método de Tukey a 5\%. O delineamento experimental usado foi o inteiramente casualizado. 


\section{RESULTADOS E DISCUSSÃO}

\subsection{Experimento de campo}

Os teores de fósforo na parte aérea e nos grãos não apresentaram diferença significativa pelo método de Tukey a 5\%, enquanto a produção de matéria seca diferiu estatisticamente. Porém, o número de plantas coletado em cada parcela não foi representativo, acarretando a elevada variação entre repetições, prejudicando os resultados obtidos quanto a estes parâmetros, os quais foram desconsiderados no trabalho.

Os teores de fósforo nas folhas, coletadas segundo Raij (1991), apresentaram grande variação a $5 \%$ de significância, tendo variado de $2,49 \mathrm{~g} \mathrm{~kg}^{-1}$ a 3,19 para os híbridos AG6690 e P3072, respectivamente (tabela 3). Dividindo os híbridos em três classes quanto ao acúmulo de $\mathrm{P}$ nas folhas, obtém-se os de menor capacidade de acúmulo (2,49 e 2,59 $\mathrm{g} \mathrm{kg}^{-1}$ ), AG6690, PX1318H e P3021, os de maior acúmulo (acima

de 3,13 $\mathrm{g} \mathrm{kg}^{-1}$ ), P3072, AG6018, P30R07, P30F33 e ZN8474, e os de acúmulo intermediário, onde se situam os demais híbridos estudados. 
Tabela 3: Teores de $\mathrm{P}\left(\mathrm{g} \mathrm{kg}^{-1}\right)$ nas folhas e produtividade $\left(\mathrm{kg} \mathrm{ha}^{-1}\right)$ de híbridos de milho.

\begin{tabular}{|c|c|c|}
\hline \multirow[t]{2}{*}{ Híbrido } & Produtividade & $P$ folha \\
\hline & $\mathrm{kg} \mathrm{ha}^{-1}$ & $\mathrm{~g} \mathrm{~kg}^{-1}$ \\
\hline P30K 75 & $9.282 \mathrm{a}$ & 2,77 cdefghi \\
\hline P3021 & $9.262 \mathrm{a}$ & $2,59 \mathrm{hi}$ \\
\hline P30F33 & $9.224 \mathrm{ab}$ & $3,15 \mathrm{ab}$ \\
\hline P30R07 & $9.096 \mathrm{abc}$ & $3,17 \mathrm{ab}$ \\
\hline AG6018 & $9.067 \mathrm{abc}$ & $3,19 a$ \\
\hline C813 & $8.759 \mathrm{abcd}$ & 2,94 abcdef \\
\hline PX1318H & $8.746 \mathrm{abcd}$ & $2,49 \mathrm{i}$ \\
\hline P30F45 & $8.726 \mathrm{abcd}$ & 2,78 cdefghi \\
\hline DINA766 & $8.655 \mathrm{abcd}$ & 2,69 efghi \\
\hline AG6690 & 8.577 abcd & $2,49 \mathrm{i}$ \\
\hline P3071 & $8.545 \mathrm{abcd}$ & 2,94 abcdef \\
\hline PX1318J & 8.485 abcde & 2,75 cdefghi \\
\hline PX1268Z & 8.459 abcde & 2,86 bcdefgh \\
\hline C909 & $8.382 \mathrm{abcdef}$ & 2,95 abcde \\
\hline C333B & 8.277 abcdef & 2,74 defghi \\
\hline P30F80 & 8.223 bcdef & 2,88 abcdefgh \\
\hline P3041 & 8.202 bcdef & 2,79 cdefghi \\
\hline P30F88 & $8.189 \mathrm{cdef}$ & 3,01 abcd \\
\hline ZN8420 & $8.175 \mathrm{cdef}$ & 2,60 ghi \\
\hline TORK & $8.007 \mathrm{def}$ & 2,91 abcdef \\
\hline P3072 & $7.902 \mathrm{def}$ & $3,19 \mathrm{a}$ \\
\hline P3081 & $7.871 \mathrm{def}$ & $3,05 \mathrm{abcd}$ \\
\hline ZN8474 & $7.771 \mathrm{def}$ & $3,13 \mathrm{ab}$ \\
\hline C747 & $7.457 \mathrm{efg}$ & 2,77 cdefghi \\
\hline ZN8550 & $7.392 \mathrm{fg}$ & 2,93 abcdef \\
\hline C929 & $6.722 \mathrm{~g}$ & 2,63 fghi \\
\hline CRUZ & $5.469 \mathrm{~h}$ & $3,06 a b c$ \\
\hline $\mathrm{F}$ & $19,38^{*}$ & $13,32 *$ \\
\hline CV $(\%)$ & 4,36 & 3,87 \\
\hline Média & 8.334 & 2,87 \\
\hline
\end{tabular}


Quanto à produtividade (tabela 3), houve grande diferença entre os híbridos estudados, sendo que a produtividade média do experimento foi de $8,3 \mathrm{t} \mathrm{ha}^{-1}$, bastante acima da média nacional, 3,2 $\mathrm{t} \mathrm{ha}^{-1}$ na safra 2000/2001, segundo a CONAB. Na fazenda onde foi conduzido o experimento, a produtividade média é de $7 \mathrm{t} \mathrm{ha}{ }^{-1}$, já bem mais elevada que a nacional, segundo o Sr. Pagnussatt, agricultor na região.

Os mais produtivos foram os híbridos P30K75, P3021 e o P30F33 com rendimentos de 9.282, 9.262 e $9.224 \mathrm{~kg} \mathrm{ha}^{-1}$, respectivamente. Entretanto, os híbridos ZN8550, C929 e CRUZ produziram respectivamente $7.392,6.722$ e $5.469 \mathrm{~kg} \mathrm{ha}^{-1}$. Isso vem comprovar que dentre os híbridos atualmente recomendados para cultivo na região do cerrado ainda existe grande diferenciação em termos produtivos e de adaptações com possibilidades de melhor utilização do $\mathrm{P}$, principalmente, em solos deficientes como ocorre no cerrado brasileiro.

Essas diferenças podem ser fruto de adaptações genéticas ocorridas durante anos de cultivo, estando de acordo com numerosos trabalhos que mostram variações adaptativas em culturas sob estresse nutricional, justificando a importância de trabalhos como este na seleção de genótipos mais produtivos para os atuais sistemas de cultivos (Baker et al., 1970; Nielsen \& Barber 1978; Schenk \& Barber 1979; Furlani et al., 1985; Thung, 1990; Machado et al., 1999; Parentoni et al., 1999).

Segundo Blair ${ }^{4}$ e Horst et al $^{5}$., citados por Machado et al. (1999), os híbridos mais eficientes são aqueles que apresentam alta produção de grãos com menor acúmulo de nutriente nos mesmos. Neste sentido, os híbridos P3021, C813, PX1318H e o P3072 destacaram-se como mais eficientes, apresentando maior rendimento de grãos por unidade de $\mathrm{P}$ acumulado nos grãos, além de menor remoção do nutriente do sistema produtivo, enquanto os híbridos P3071, P30F80 e P30F45 foram os menos eficientes, removendo mais $\mathrm{P}$ do sistema produtivo.

\footnotetext{
${ }^{4}$ BLAIR, G. Nutrient efficiency: what do we really mean? In: RANDALL, P.J.; DELHAITZE, E.; RICHARDS, R.A.; MUNNS, R. (Ed.) Genetic aspects of plant mineral nutrition. Dordrecht: Kluwer Academic, 1993. p.205-13.

${ }^{5}$ HORST, W.J.; ABDOU, M.; WIESLER, F. Genotypic differences in phosphorus efficiency of wheat. Plant and Soil, v.155/156, p.293-6. 1974.
} 
Entretanto, Clarck \& Brown (1974) consideram plantas eficientes em P como aquelas que acumulam maiores concentrações do nutriente quando cultivadas em um certo nível do mesmo. Sendo assim, os híbridos mais eficientes seriam o P30F45, P30F33 e o P3041. Porém, no presente trabalho, além de selecionar os híbridos que apresentam maiores rendimentos de grãos por área sob as condições nutricionais da região onde são cultivados, dentre os quais estão os híbridos P30K75, P3021 e o P30F33 com rendimento acima de $9.000 \mathrm{~kg} \mathrm{ha}^{-1}$, serão selecionados os mais eficientes na absorção de $\mathrm{P}$ do solo, através da atividade específica de ${ }^{32} \mathrm{P}$.

\subsection{Experimento de avaliação de espécies}

Este ensaio foi conduzido com a finalidade de avaliar culturas quanto à eficiência na absorção do fósforo do solo, determinando deste modo a cultura a ser comparada com o milho, principal objetivo do trabalho.

Durante a condução do ensaio foram observados alguns problemas ligados a possíveis deficiências nutricionais e condições climáticas como o excesso de temperatura. Aos 18 dias após o plantio as plantas de algodão apresentaram clorose nas bordas das folhas velhas avançando para necrose, possivelmente relacionada à falta de potássio, uma vez que o solo usado apresentava baixos teores de K. O milho apresentou inicio de arroxeamento da base das folhas velhas em todos os vasos, sintoma característico da deficiência de $\mathrm{P}$, já que o solo é pobre em $\mathrm{P}$ disponível $\left(5,4 \mathrm{mg} \mathrm{dm}^{-3}\right)$.

Aos 25 dias, o caupi começou a apresentar queda de folhas, momento em que foi consultado o professor Hiroshi Kimati do Departamento de Entomologia, Fitopatologia e Zoologia Agrícola da ESALQ/USP, que por experiências já ocorridas, informou que não era problema fitopatológico nem nutricional, mas sim uma queima das folhas por excesso de temperatura dentro da casa de vegetação. Braum \& Helmke (1995) trabalhando com tremoço branco e soja em experimentos de casa de vegetação também observaram que altas temperaturas prejudicaram o desenvolvimento do tremoço. $\mathrm{O}$ girassol e o milho também apresentaram queima nas pontas e bordas das folhas velhas podendo ser um problema de deficiência de K. Já aos 27 dias, o feijão também começou 
a apresentar clorose nas pontas e bordas das folhas velhas, possivelmente por falta de K. $\mathrm{O}$ amendoim entrou na fase reprodutiva, iniciando o florescimento. Um dos problemas de se trabalhar com diferentes culturas no mesmo período é a impossibilidade de avaliar as plantas no mesmo estádio de desenvolvimento, uma vez que os ciclos são diferentes, como citado por Hocking et al. (1997).

O trigo e a cevada apresentaram secamento de folhas velhas e crescimento estagnado durante todo o experimento, permanecendo raquíticos até o final. Isso se deve possivelmente a dois fatores: baixa fertilidade do solo e, elevada acidez uma vez que são culturas cultivadas no Sul do país em solos mais férteis, portanto os resultados referentes a estas culturas devem ser considerados com ressalva.

Quanto ao teor de fósforo na planta e a atividade específica de ${ }^{32} \mathrm{P}(\mathrm{S})$ houve grande variação entre as culturas avaliadas. Os teores de $\mathrm{P}$ variaram de $0,44 \mathrm{~g} \mathrm{~kg}^{-1}$ a 2,39 $\mathrm{g} \mathrm{kg}^{-1}$, sendo que nos extremos estão a braquiária e o caupi, respectivamente (tabela 4) e

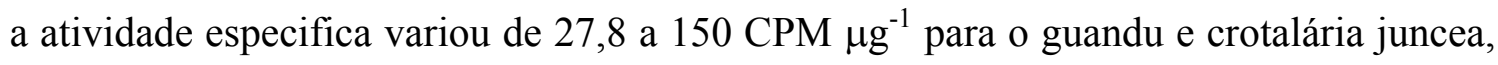
respectivamente (figura 2 e tabela $1 \mathrm{~A}$ ).

$\mathrm{O}$ conteúdo de $\mathrm{P}$ na parte aérea diferiu entre as culturas estudadas, sendo que o caupi foi o que apresentou maior conteúdo de $\mathrm{P}, 2,39 \mathrm{~g} \mathrm{~kg}^{-1}$, diferindo das demais culturas. Em seguida, ficou o stylosantes, apresentando $2,08 \mathrm{~g} \mathrm{~kg}^{-1}$, também diferindo das demais culturas. O feijão, crotalária juncea, amendoim e a aveia preta estão logo abaixo, não diferindo entre si, cujos teores de $\mathrm{P}$ variaram de 1,35 a $1,63 \mathrm{~g} \mathrm{~kg}^{-1}$. A braquiária, sorgo, mucuna preta e cevada foram as culturas que apresentaram menor acumulo de fósforo na parte aérea, cujos teores vaiaram de 0,44 a $0,73 \mathrm{~g} \mathrm{~kg}^{-1}$. O algodão, tremoço branco, milho, guandu e arroz apresentaram acúmulos de P ligeiramente mais elevados que as culturas anteriores. Na tabela 4 são apresentados os teores acumulados de P na parte aérea. 
Tabela 4: Teores de P na parte aérea das plantas cultivadas em solo de cerrado.

\begin{tabular}{|c|c|}
\hline Cultura & $P\left(\mathrm{~g} \mathrm{~kg}^{-1}\right)$ \\
\hline Crotalária & $1,36 \mathrm{~cd}$ \\
\hline Caupi & $2,39 \mathrm{a}$ \\
\hline Soja & $1,15 \mathrm{~d}$ e $\mathrm{f}$ \\
\hline Stylosantes & $2,08 \mathrm{~b}$ \\
\hline Girassol & $1,28 \mathrm{de}$ \\
\hline Amendoim & $1,35 \mathrm{c} \mathrm{d}$ \\
\hline Milheto & $1,18 \mathrm{~d}$ e $\mathrm{f}$ \\
\hline Sorgo & $0,67 \mathrm{~h} \mathrm{i}$ \\
\hline Aveia & $1,35 \mathrm{c} \mathrm{d}$ \\
\hline Milho & $0,83 \mathrm{~g} \mathrm{~h}$ \\
\hline Braquiária & $0,44 \mathrm{i}$ \\
\hline Feijão & $1,63 \mathrm{c}$ \\
\hline Trigo & $1,23 \mathrm{de}$ \\
\hline Mucuna & $0,68 \mathrm{~h} \mathrm{i}$ \\
\hline Tomate & 1,00 e $f \mathrm{~g}$ \\
\hline Triticale & $1,20 \mathrm{de} \mathrm{f}$ \\
\hline Cevada & $0,73 \mathrm{gh} \mathrm{i}$ \\
\hline Tremoço & $0,80 \mathrm{gh}$ \\
\hline Arroz & $0,93 \mathrm{f} \mathrm{g} \mathrm{h}$ \\
\hline Eucalipto & 0,99 e $\mathrm{fg}$ \\
\hline Algodão & $0,77 \mathrm{~g} \mathrm{~h}$ \\
\hline Guandu & $0,92 \mathrm{fgh}$ \\
\hline $\mathrm{F}$ & $71,79^{*}$ \\
\hline CV (\%) & 8,27 \\
\hline Média & 1,13 \\
\hline
\end{tabular}

Hocking et al. (1997), estudando sete espécies de plantas quanto à capacidade de acessar o fósforo pouco disponível em solo pobre neste nutriente, observaram que o tremoço branco foi o que mais acumulou $P$ na parte aérea, enquanto a canola foi a que menos acumulou, o guandu, girassol e soja apresentaram valores intermediários, concordando com os resultados obtidos neste trabalho. Ainda como plantas que acumularam mais P, não estudadas por Hocking et al. (1997), estão o caupi, stylosantes 
e o feijão, assim como as que menos acumularam como a braquiária, sorgo e mucuna preta. Porém, os resultados de acumulo de $\mathrm{P}$ não indicam que as plantas são mais ou menos eficientes no aproveitamento do P pouco disponível do solo, uma vez que grande parte deste nutriente acumulado pode ser proveniente do fertilizante, sendo que cada cultura pode desenvolver diferentes meios para obter os nutrientes necessários num ambiente pobre, ou ainda, como sugerido por Machado (2000), algumas plantas desenvolvem estratégias que minimizem a necessidade do nutriente, decorrentes de diferenças metabólicas, apresentando bons rendimentos mesmo com pouco nutriente disponível, como observado no experimento anterior no qual a produtividade dos híbridos de milho variou de 5,5 a 9,3 toneladas de grãos por hectare.

Os valores de atividade específica estão apresentados na figura 2 e na tabela 1A. Pode-se notar grande variação entre as culturas avaliadas, sendo que a crotalária juncea e o caupi foram os apresentaram maior atividade específica, 150 e 142,6 CPM $\mu \mathrm{g}^{-1}$ respectivamente, enquanto o arroz, eucalipto, algodão e guandu apresentaram

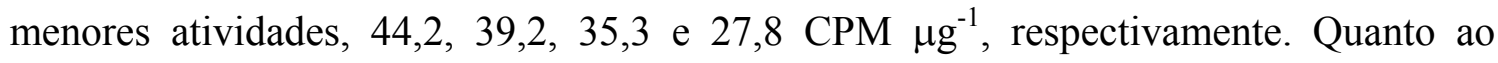
guandu e feijão, sua germinação não ocorreu juntamente com as demais espécies, cujos resultados devem ser considerados com ressalvas neste trabalho.

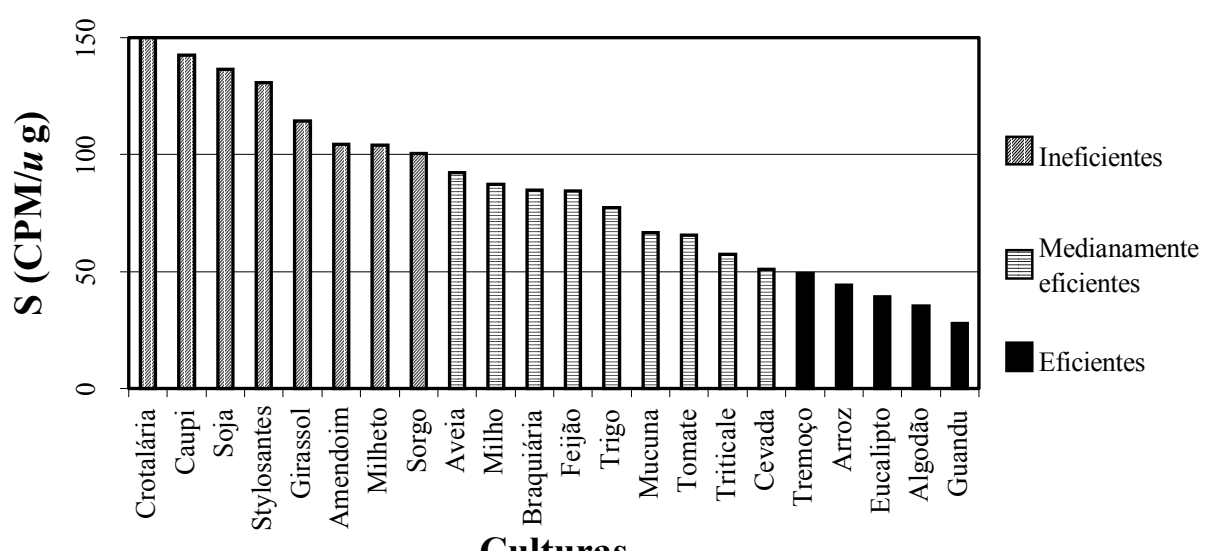

Figura 2: Classificação das culturas de acordo com a atividade específica $\left(\mathrm{CPM} \mu \mathrm{g}^{-1}\right)$. 
Como todas as espécies foram submetidas à mesma concentração de $\mathrm{P}$ no solo, suas atividades especificas podem ser comparadas e se todos fossem igualmente eficientes, a atividade seria igual. Sendo assim, uma menor atividade (menor radioatividade) de P indica, de acordo com Hocking et al. (1997), que a cultura é mais capaz de acessar o fósforo pouco disponível do solo. Conseqüentemente, o algodão e o eucalipto foram as culturas mais capazes de absorver o fósforo do solo, então mais eficientes a P. Esta melhor eficiência pode ser atribuída a diversos fatores, como formação de raízes proteoides, observadas em tremoço branco, liberação de ácidos pelo sistema radicular em guandu, segundo Hocking et al. (1997), acidificação da rizosfera pela liberação de prótons na absorção de cátions (Loss et al $^{6}$., citado por Hocking et al., 1997), ou ainda a mudanças adaptativas na rizosfera de natureza fisiológica, bioquímica e molecular (Raghathama, 1999).

Quanto a crotalária juncea e o caupi devido sua maior atividade específica de ${ }^{32} \mathrm{P}$, são consideradas menos eficientes na absorção do fósforo do solo, sendo mais dependentes do fósforo disponível do solo e conseqüentemente, da adição de $\mathrm{P}$ via fertilizante quando cultivados em solos pobres neste nutriente.

A mucuna preta, tomate, triticale, tremoço branco e o arroz, neste trabalho, não diferiam estatisticamente do eucalipto e algodão quanto à atividade especifica, porém apresentaram valores ligeiramente mais elevados, indicando menor eficiência na absorção de P. Nos trabalhos de Braum \& Helmke (1995) e Hocking et al. (1997), nos quais o tremoço branco foi comparado com a soja (em ambos os trabalhos) e com canola, tremoço azul, guandu, girassol e trigo (no último), ele apresentou maior eficiência na absorção de fósforo. Contudo, o presente trabalho vem adicionar informações aos citados acima, indicando que o algodão, o eucalipto e o arroz, não estudados por eles, são mais eficientes que o tremoço branco até então tido como superior.

${ }^{6}$ LOSS, S.P.; ROBSON, A.D.; RITCHIE, G.S.P. $\mathrm{H}^{+} / \mathrm{OH}^{-}$excretion and nutrient uptake in upper and lower parts of lupin (Lupinus angustifolius L.) root systems. Ann. Bot., v.72, p.315-20, 1993. 
As culturas estudadas foram agrupadas, em três classes de eficiência na absorção de $\mathrm{P}$ de acordo com os valores da atividade especifica. As consideradas ineficientes situadas na faixa de 100 a $150 \mathrm{CPM} \mu^{-1}$ que seriam a crotalária juncea, caupi, soja, stylosantes, girassol, amendoim, milheto e sorgo. Na faixa de 50 a $100 \mathrm{CPM}$ $\mu \mathrm{g}^{-1}$ estariam as medianamente eficientes como a aveia preta, milho, braquiária, feijão, trigo, mucuna preta, tomate, triticale e cevada. O algodão, eucalipto, arroz, tremoço branco e guandu podem ser considerados eficientes na absorção do P pouco disponível do solo (figura 2).

Para o cerrado, devido à pobreza natural dos solos em $\mathrm{P}$, em solos não adubados, a crotalária juncea não seria uma boa opção para adubação verde, assim como uma rotação de culturas de milho com caupi, soja, pastagem de stylosantes ou girassol devem ser conduzidas com muito cuidado quanto à adubação fosfatada, ou seja, estas culturas são pouco eficientes na absorção e utilização do $\mathrm{P}$ e altamente dependentes da adubação fosfatada para um bom desenvolvimento e rendimento, sendo que em condições nas quais adubações são feitas regularmente e de acordo com a necessidade das plantas, elas podem apresentar bons rendimentos. Entretanto a mucuna preta seria uma boa opção de adubação verde para o cerrado em condições de reduzidas adubações fosfatadas devido sua maior rusticidade e melhor eficiência na absorção de $\mathrm{P}$ em relação a crotalária. $\mathrm{O}$ algodão também é uma boa opção de cultivo para a região do cerrado devido sua melhor eficiência na absorção do P do solo.

O milheto, aveia preta e trigo são culturas de clima frio, cultivadas em grande escala no sul do país e são menos efícientes na absorção de fósforo, sendo atualmente de pouco interesse para cultivo na região central do país.

O eucalipto possivelmente é uma das culturas arbóreas mais eficientes na absorção de P por apresentar grande sistema radicular explorando maior volume de solo, cultivado na maioria das vezes, em solos pobres nos quais outras culturas não apresentam bom rendimento. 


\subsection{Experimento de avaliação de 30 híbridos de milho}

O objetivo deste experimento foi o de selecionar, entre os híbridos recomendados para a região do cerrado, os mais eficientes na absorção de fósforo do solo, cultivados em um solo cultivado durante 20 anos e em um solo sob vegetação natural de cerrado. Foram avaliados a produção de matéria seca da parte aérea, acúmulo de fósforo nas plantas e a atividade específica de ${ }^{32} \mathrm{P}$.

Neste experimento foram avaliados 30 híbridos de milho, porém, existem novos híbridos que não estavam presentes no primeiro experimento por terem sido lançados no mercado posteriormente, assim como alguns dos híbridos estudados no primeiro experimento não foram avaliados neste experimento por falta de sementes, ou por terem saído do mercado.

No solo natural, aos 12 dias após a germinação foi observado que na maioria dos vasos havia raízes na superfície do solo, resultado da elevada acidez e da sensibilidade das plantas. Os híbridos C747, P3071, ZN8550, ZN8410 e o P3041 foram os que apresentaram maior quantidade de raízes na superfície do solo, provavelmente mais sensíveis à acidez. Também aos 12 dias após a germinação, já se notou grande diferença no desenvolvimento das plantas quanto à altura, sendo que no solo natural as

mesmas estavam menores que no cultivado. Aos 18 dias a maioria dos híbridos já apresentava sintomas de deficiência de $\mathrm{P}$, arroxeamento de folhas velhas.

Durante todo o ensaio os híbridos cultivados no solo natural apresentaram reduzido crescimento e permaneceram raquíticos, com grandes problemas de falta de fósforo e deficiências nutricionais generalizadas. Assim, os resultados obtidos para o solo natural devem ser considerados com ressalvas, uma vez que somente híbridos mais rústicos apresentaram desenvolvimento ligeiramente melhor. Já no solo cultivado, houve variação no desenvolvimento das plantas, assim como alguns híbridos apresentaram sintomas claros de deficiência de $\mathrm{P}$, porém menos intensos que no solo natural. No momento do corte das plantas, 30 dias após a germinação, os híbridos DINA766, TORK, C813, ZN8420 e AG9090 apresentaram arroxeamento nas folhas velhas, sintoma de carência em P, porém, os híbridos C813 e ZN8420 apresentaram elevada eficiência na 
absorção de $\mathrm{P}$, sendo que o arroxeamento observado é uma característica da planta e não sintoma de deficiência de P. Já os demais, apresentaram eficiência intermediária, indicando que a coloração observada é decorrente de falta de P.

Quanto à produção de matéria seca, houve diferença significativa entre os híbridos estudados em ambos os solos. No solo natural, como já foi tratado anteriormente, devido à quantidade muito pequena de fósforo disponível ( $\mathrm{P}$ resina $=5,4$ $\mathrm{mg} \mathrm{dm}^{-3}$ ) dificultando a extração pelas plantas, elas se desenvolveram pouco, cuja matéria seca da parte aérea foi 2 a 4 vezes menor que no solo cultivado há 20 anos, para todos os híbridos, com uma média de produção de 1,08g por vaso. Os híbridos ZN8471, ZN8410 e o tremoço branco foram os que produziram mais parte aérea, enquanto o TORK, C813 e AG9090 foram os que menos produziram quando plantados no solo natural.

No solo cultivado, houve grande variação na produção de matéria seca entre os híbridos (tabela 5), variando de 1,71 a 4,56g, sendo que os híbridos ZN8550, P3021 e P30K75 foram os mais produtivos, 4,56, 4,49 e 4,40g, respectivamente, enquanto os híbridos AG9090, C813 e TORK foram os menos produtivos, 1,71, 1,88 e 2,04g respectivamente. 
Tabela 5: Produção de matéria seca (MS) e acúmulo de $\mathrm{P}$ na parte aérea por híbridos de milho e tremoço branco avaliados em solo de cerrado "cultivado".

\begin{tabular}{|c|c|c|}
\hline Híbrido & MS (g) & $P\left(\mathrm{~g} \mathrm{~kg}^{-1}\right)$ \\
\hline P30F80 & $3,52 \mathrm{abcdef}$ & $2,13 \mathrm{abcd}$ \\
\hline C909 & 3,41 abcdef & $2,22 \mathrm{ab}$ \\
\hline PX1409K & $3,91 \mathrm{abcde}$ & $2,13 \mathrm{a} \mathrm{b} \mathrm{c} \mathrm{d}$ \\
\hline C333B & $3,92 \mathrm{abcde}$ & $1,95 \mathrm{abcd}$ \\
\hline P30F88 & $4,04 \mathrm{a} \mathrm{b} \mathrm{c} \mathrm{d}$ & $2,03 \mathrm{a} \mathrm{b} \mathrm{c} \mathrm{d}$ \\
\hline P3081 & $3,89 \mathrm{abcde}$ & $1,96 \mathrm{abcd}$ \\
\hline P3071 & $3,46 \mathrm{abcdef}$ & $2,23 \mathrm{ab}$ \\
\hline DINA766 & $2,92 \mathrm{de} \mathrm{g} h$ & $2,24 \mathrm{ab}$ \\
\hline P3041 & $3,76 a b c d e f$ & $2,07 \mathrm{a} \mathrm{b} \mathrm{c} \mathrm{d}$ \\
\hline P3021 & $4,49 a b$ & $1,64 \mathrm{~d}$ \\
\hline ZN8452 & $4,34 \mathrm{abc}$ & $2,41 \mathrm{a}$ \\
\hline AG7575 & $3,83 a b c d e f$ & $2,10 \mathrm{abcd}$ \\
\hline C747 & $3,70 \mathrm{abcdef}$ & $1,94 \mathrm{a} \mathrm{b} \mathrm{c} \mathrm{d}$ \\
\hline DKB911 & $4,09 a b c d$ & $1,86 \mathrm{bc} \mathrm{d}$ \\
\hline AG6018 & $3,76 a b c d e f$ & $2,09 \mathrm{abcd}$ \\
\hline ZN8550 & $4,56 \mathrm{a}$ & $1,73 \mathrm{bc} \mathrm{d}$ \\
\hline PX1379F & $3,96 a b c d e$ & $1,72 \mathrm{bcd}$ \\
\hline TORK & $2,04 \mathrm{gh}$ & $1,88 \mathrm{a} \mathrm{b} \mathrm{c} \mathrm{d}$ \\
\hline ZN8410 & $3,86 \mathrm{abcde}$ & $2,17 \mathrm{a} \mathrm{bc}$ \\
\hline P30K75 & $4,40 \mathrm{ab}$ & $1,71 \mathrm{bcd}$ \\
\hline AG9090 & $1,71 \mathrm{~h}$ & $1,97 \mathrm{a} \mathrm{b} \mathrm{c} \mathrm{d}$ \\
\hline PX1359G & $3,22 \mathrm{bcdefg}$ & $1,65 \mathrm{c} \mathrm{d}$ \\
\hline P3027 & $2,65 \mathrm{e} \mathrm{fgh}$ & $1,81 \mathrm{bc} \mathrm{d}$ \\
\hline PX1339F & $2,50 \mathrm{fgh}$ & $1,78 \mathrm{~b} \mathrm{c} \mathrm{d}$ \\
\hline P30F33 & $3,47 \mathrm{abcdef}$ & $2,00 \mathrm{abcd}$ \\
\hline DINA657 & $3,26 a b c d e f g$ & $2,10 \mathrm{abcd}$ \\
\hline ZN8471 & $4,05 \mathrm{abcd}$ & $1,81 \mathrm{~b} \mathrm{c} \mathrm{d}$ \\
\hline C813 & $1,88 \mathrm{~h}$ & $1,61 \mathrm{~d}$ \\
\hline $\mathrm{P} 30 \mathrm{~F} 45$ & $2,90 \mathrm{de} \mathrm{gh}$ & $1,79 \mathrm{bcd}$ \\
\hline ZN8420 & $3,02 \mathrm{cde} f \mathrm{gh}$ & $1,97 \mathrm{abcd}$ \\
\hline Tremoço & $2,52 \mathrm{fgh}$ & $0,99 \mathrm{e}$ \\
\hline $\mathrm{F}$ & $10,13^{*}$ & $7,69^{*}$ \\
\hline CV $(\%)$ & 11,99 & 8,63 \\
\hline Média & 3,45 & 1,93 \\
\hline
\end{tabular}


Os resultados obtidos mostram mais uma vez que há grande variação na matéria seca produzida por híbridos de milho quando cultivados em solos pobres em $\mathrm{P}$ disponível.

Quanto aos teores de P na planta (tabela 5), também houve grande variação entre os híbridos, nos dois solos utilizados, porém, os resultados do solo natural não serão comentados, como justificado acima.

No solo cultivado, o conteúdo médio de $\mathrm{P}$ na planta foi de $1,93 \mathrm{~g} \mathrm{~kg}^{-1}$, sendo que os teores variaram entre $0,93 \mathrm{~g} \mathrm{~kg}^{-1}$ para o tremoço branco e $2,41 \mathrm{~g} \mathrm{~kg}^{-1}$ para o híbrido ZN8452. Este acúmulo de $\mathrm{P}$ não indica que plantas são mais ou menos eficientes, uma vez que diferentes híbridos através de adaptações genéticas podem se desenvolver e produzir bem com menor quantidade de P, ou seja, plantas com alta quantidade de $\mathrm{P}$ podem não ser mais produtivas e vice-versa, de acordo com Machado (2000). Baker et al. (1970) e Machado et al. (1999) também mostraram haver diferenças geneticamente controladas no acúmulo de $\mathrm{P}$ por híbridos de milho, mas que este acúmulo não estava relacionado com a habilidade das plantas em extrair $\mathrm{P}$ do solo. Já Furlani et al. (1985), trabalhando com linhagens de milho em solução nutritiva, observou pequena variação no acúmulo de $\mathrm{P}$ nas partes da planta, discordando do presente trabalho. Isto pode ser justificado, pois no trabalho acima os autores compararam as linhagens em solução nutritiva, que por sua vez não apresenta problemas de fixação do $\mathrm{P}$ aplicado, como neste trabalho cujo solo é potencialmente responsável pela retenção de grande parte do $\mathrm{P}$ presente no sistema.

Para selecionar os híbridos mais eficientes, foram calculadas as atividades específicas de ${ }^{32} \mathrm{P}$ para cada um em ambos os solos, sendo que somente os resultados referentes ao solo cultivado serão apresentados na figura 3 e tabela $2 \mathrm{~A}$, e os referentes ao natural mais adiante. As plantas cultivadas neste último apresentaram desenvolvimento reduzido devido à quantidade muito baixa de $\mathrm{P}$ total no solo $(225,7 \mathrm{mg}$ $\mathrm{dm}^{-3}$ ), grande parte deve estar fortemente adsorvido aos colóides e conseqüentemente muito pouco disponível para as plantas, onde nenhum híbrido pode ter sido capaz de extrair o P do solo. 
Se todos os híbridos fossem idênticos quanto à eficiência na absorção de $\mathrm{P}$, $\mathrm{e}$ por terem sido cultivados no mesmo solo sob as mesmas condições, eles deveriam apresentar a mesma atividade específica, ou seja, a relação $\mathrm{CPM} / \mu \mathrm{g}$ de $\mathrm{P}$ presente na planta seria igual. Mas como visto anteriormente, vários trabalhos mostram diferenças adaptativas entre espécies de plantas (Rorison, 1968; Furlani et al., 1985; Sawazaki \& Furlani, 1987; Macedo, 1996; Bahia Filho et al., 1997; Hocking et al., 1997) e mesmo entre genótipos de milho (Anghinoni et al., 1989; Baligar et al., 1997; Machado et al., 1999; Parentoni et al., 1999; Machado, 2000), logo, a atividade específica de ${ }^{32} \mathrm{P}$ deve diferir entre os híbridos, como ocorreu no presente trabalho.

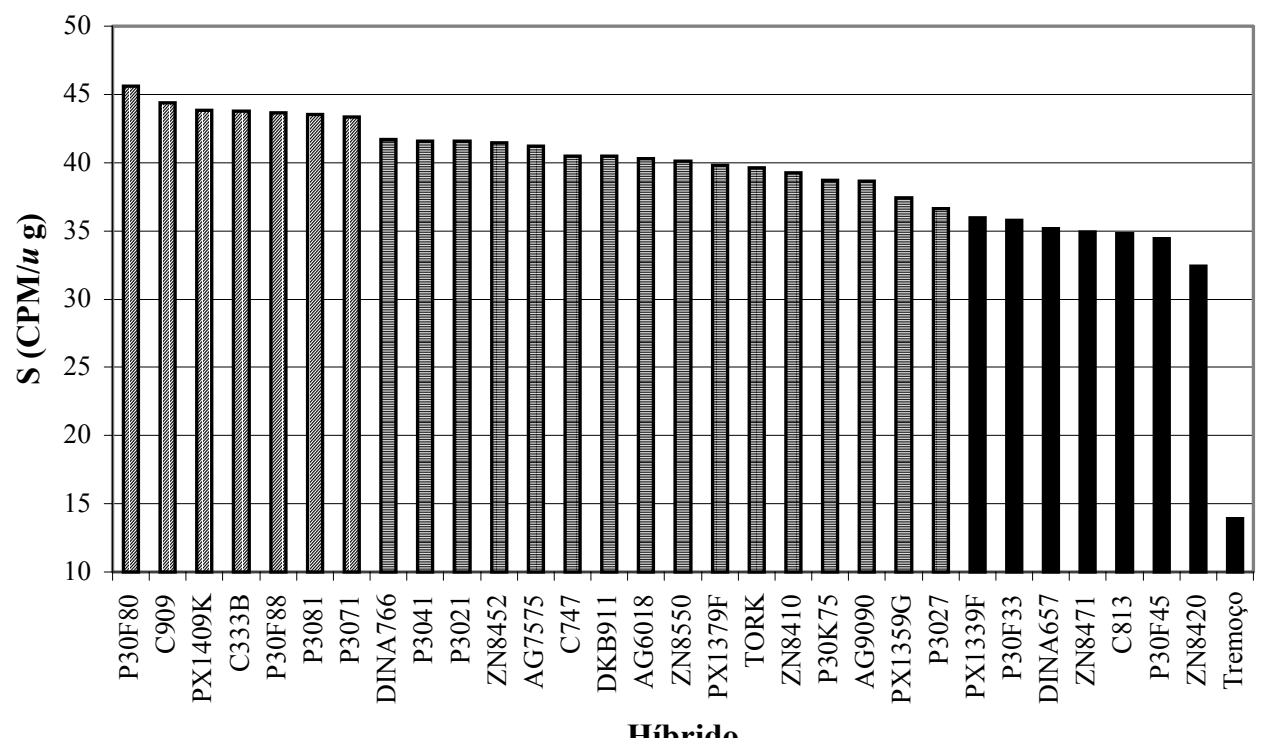

Figura 3: Classificação dos híbridos como: $\square$ Ineficiente, 曰 Medianamente eficiente e Eficiente, de acordo com a atividade específica $\left(\mathrm{CPM} \mu \mathrm{g}^{-1}\right)$.

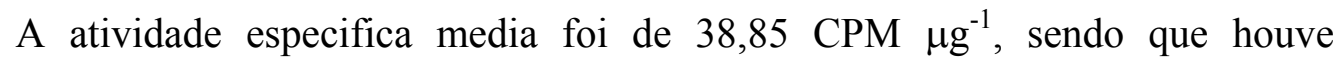
diferença entre os híbridos estudados. Os híbridos P30F80 e C909 foram os que apresentaram maior atividade específica, 45,63 e 44,37 $\mathrm{CPM} \mu^{-1}$, respectivamente, sendo considerados ineficientes segundo Hocking et al. (1997), enquanto o ZN8420, P30F45, C813, DINA657 e P30F33 foram mais eficientes na absorção do P do solo, 


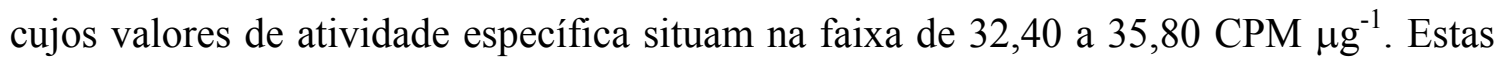
diferenças na eficiência a P podem ser herdadas geneticamente através do cruzamento de linhagens capazes de produzir híbridos mais eficientes em condições de estresse de fósforo, como observado por Parentoni et al (1999) quando avaliou híbridos simples obtidos de linhagens eficientes.

O tremoço branco, considerado por Hocking et al. (1997) como cultura mais eficiente na absorção de $\mathrm{P}$ pouco disponível do solo, e utilizado neste experimento como cultura de referencia, também foi mais eficiente que todos os híbridos estudados, apresentando uma atividade especifica 2,3 vezes menor que a do melhor híbrido, cujo

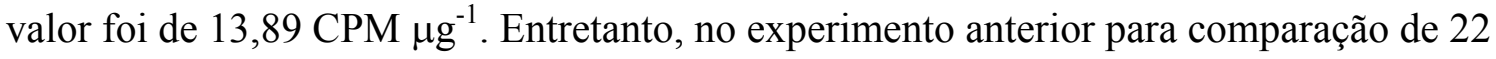
culturas, o tremoço branco foi menos eficiente que o arroz, eucalipto e algodão, este último considerado mais eficiente, porém ainda na faixa das culturas mais eficientes na absorção do fósforo do solo.

Os híbridos avaliados foram divididos em três classes quanto a sua eficiência na absorção de fósforo. Ineficientes, cuja atividade específica foi maior que 42,0 CPM $\mu \mathrm{g}^{-1}$, medianamente eficientes, com valores entre 36,0 e 42,0 CPM $\mu \mathrm{g}^{-1}$, e eficientes, cuja atividade especifica foi menor que $36,0 \mathrm{CPM} \mu \mathrm{g}^{-1}$, como ilustrado na figura 3 .

De acordo com os resultados, dentre os híbridos atualmente recomendados para a região do cerrado, o ZN8420, P30F45, C813, ZN8471, DINA657, P30F33 e PX1339F são os mais adequados para o cultivo devido suas melhores eficiências na absorção do fósforo pouco disponível do solo, podendo levar a maiores rendimentos, dentre os quais o híbrido P30F33 está entre os mais produtivos, com rendimentos superiores a 9,0 $\mathrm{tha}^{-1}$ como observado no experimento de campo.

No solo natural, como comentado anteriormente, as plantas apresentaram desenvolvimento relativamente reduzido, com produção de matéria seca 2 a 4 vezes menor que quando plantadas no solo "cultivado" (tabela 6), devido a baixa fertilidade do solo natural em todos os nutrientes, elevada acidez, baixa saturação por bases e, principalmente, devido o teor muito baixo de P. Os híbridos ZN8471 e ZN8410 são menos sensíveis a estas condições, produzindo mais parte aérea, enquanto o TORK, C813 e AG9090 foram os mais prejudicados, sendo que no solo cultivado estes híbridos 
também foram os menos produtivos em termos de parte aérea, indicando uma baixa capacidade de crescimento nestes dois tipos de solo.

Quanto à atividade específica (tabela 6), houve grande diferença entre os híbridos no solo natural, sendo que a atividade média foi de 2,91 $\mathrm{CPM} \mathrm{gg}^{-1}$, muito inferior à média no solo cultivado, além do menor acúmulo de $\mathrm{P}$ na parte aérea das plantas cultivadas no solo natural $\left(0,91 \mathrm{~g} \mathrm{~kg}^{-1}\right)$. O resultado deste baixo acúmulo de $\mathrm{P}$ e baixa atividade específica $(\mathrm{S})$ é devido ao reduzido teor de fósforo no solo e à alta fixação do ${ }^{32} \mathrm{P}$ aplicado.

Neste solo, os híbridos com $\mathrm{S}$ menor que 2,4 $\mathrm{CPM} \mu \mathrm{g}^{-1}$, são considerados eficientes na absorção de fósforo do solo, apesar do pequeno crescimento, como

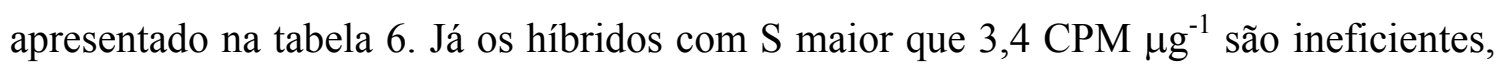
enquanto os demais são considerados medianamente eficientes, lembrando que estes resultados devem ser considerados com ressalvas, pois as plantas podem não ter expressado seu potencial na absorção de P devido a grande fixação pelo solo e baixa fertilidade, prejudicando seu desenvolvimento. 
Tabela 6: Atividade específica (S) e matéria seca (MS) da parte aérea de híbridos avaliados em solo de cerrado "natural".

\begin{tabular}{|c|c|c|}
\hline Híbrido & $\mathbf{S}\left(\mathrm{CPM} \mu \mathrm{g}^{-1}\right)$ & MS (g) \\
\hline P30F80 & $1,98 \mathrm{~g}$ & 0,903 e $\mathrm{fgh} \mathrm{i} \mathrm{j}$ \\
\hline C909 & 3,29 c d e f & $0,797 \mathrm{~h} \mathrm{i} \mathrm{j} \mathrm{k}$ \\
\hline PX1409K & $2,29 \mathrm{~g}$ & $1,263 \mathrm{a} \mathrm{b} \mathrm{c} \mathrm{d}$ \\
\hline C333B & $3,43 \mathrm{bc} \mathrm{de}$ & $0,873 \mathrm{fgh} \mathrm{i} \mathrm{j}$ \\
\hline P30F88 & $2,05 \mathrm{~g}$ & $1,123 \mathrm{bc} \mathrm{de} \mathrm{g}$ \\
\hline P3081 & $2,41 \mathrm{f} \mathrm{g}$ & $1,120 \mathrm{bcde} f \mathrm{~g}$ \\
\hline P3071 & $2,31 \mathrm{~g}$ & 0,920 e f g h i j \\
\hline DINA766 & $3,58 \mathrm{~b} \mathrm{c} \mathrm{d}$ & $0,820 \mathrm{~g} \mathrm{~h} \mathrm{i} \mathrm{j} \mathrm{k}$ \\
\hline P3041 & $3,34 \mathrm{c} \mathrm{d} \mathrm{e} \mathrm{f}$ & $0,967 \mathrm{de} \mathrm{fgh} \mathrm{i}$ \\
\hline P3021 & 2,53 e $\mathrm{f} \mathrm{g}$ & $1,330 \mathrm{a} \mathrm{b} \mathrm{c}$ \\
\hline ZN8452 & $2,12 \mathrm{~g}$ & $1,310 \mathrm{a} \mathrm{b} \mathrm{c}$ \\
\hline AG7575 & $2,84 \mathrm{~d}$ e $\mathrm{f} g$ & $1,143 \mathrm{bc} \mathrm{def}$ \\
\hline C747 & $2,26 \mathrm{~g}$ & $0,867 \mathrm{f} \mathrm{g} \mathrm{h} \mathrm{i} \mathrm{j}$ \\
\hline DKB911 & $3,48 \mathrm{~b} \mathrm{c} \mathrm{d} \mathrm{e}$ & $1,040 \mathrm{c} \mathrm{d}$ e $\mathrm{fg} \mathrm{h}$ \\
\hline AG6018 & 2,58 e $\mathrm{f} g$ & $1,163 \mathrm{bc} \mathrm{def}$ \\
\hline ZN8550 & $2,96 \mathrm{c} \mathrm{d}$ e $\mathrm{f} g$ & $1,163 \mathrm{bc} \mathrm{def}$ \\
\hline PX1379F & $2,70 \mathrm{~d}$ e $\mathrm{fg}$ & $1,207 \mathrm{bc} \mathrm{de}$ \\
\hline TORK & $3,88 \mathrm{~b} \mathrm{c}$ & $0,717 \mathrm{i} \mathrm{j} \mathrm{k}$ \\
\hline $\mathrm{ZN} 8410$ & $2,20 \mathrm{~g}$ & $1,400 \mathrm{a} \mathrm{b}$ \\
\hline P30K75 & $2,53 \mathrm{e} \mathrm{fg}$ & $1,203 \mathrm{bc} \mathrm{d} \mathrm{e}$ \\
\hline AG9090 & $6,12 \mathrm{a}$ & $0,517 \mathrm{k}$ \\
\hline PX1359G & 2,54 e $\mathrm{f} g$ & $1,140 \mathrm{bcdef}$ \\
\hline P3027 & $3,85 \mathrm{~b} \mathrm{c}$ & $1,033 \mathrm{c} \mathrm{de} \mathrm{fghi}$ \\
\hline PX1339F & $2,30 \mathrm{~g}$ & $1,177 \mathrm{bc} \mathrm{def}$ \\
\hline P30F33 & $2,22 \mathrm{~g}$ & $1,253 \mathrm{a} \mathrm{b} \mathrm{cd}$ \\
\hline DINA657 & $2,77 \mathrm{~d}$ e $\mathrm{f} g$ & $1,147 \mathrm{bc} \mathrm{def}$ \\
\hline ZN8471 & $1,98 \mathrm{~g}$ & $1,427 \mathrm{a} \mathrm{b}$ \\
\hline C813 & $4,39 b$ & $0,633 \mathrm{j} \mathrm{k}$ \\
\hline P30F45 & $3,50 \mathrm{bcde}$ & $0,967 \mathrm{de} \mathrm{fgh} \mathrm{i}$ \\
\hline ZN8420 & $3,44 \mathrm{bcde}$ & 1,173 b c d e f \\
\hline Tremoço & $2,45 \mathrm{fg}$ & $1,530 \mathrm{a}$ \\
\hline $\mathrm{F}$ & $24,90 *$ & $16,82^{*}$ \\
\hline CV (\%) & 10,44 & 9,22 \\
\hline Média & 2,91 & 1,08 \\
\hline
\end{tabular}




\section{CONCLUSÕES}

$>$ Existem diferenças adaptativas entre os híbridos quanto à produtividade de grãos em campo e quanto à eficiência na absorção de fósforo em solos de cerrado.

$>$ Os híbridos mais produtivos cultivados em solo de cerrado são o P30K75, P3021 e o P30F33 com rendimentos acima de 9,2 toneladas por hectare.

$>$ Quando o fósforo disponível no solo é muito baixo, os híbridos mais adaptados são incapazes de extrair o nutriente necessário para um bom desenvolvimento.

$>$ Dentre os híbridos estudados em campo e em casa de vegetação, o P30F33 foi o que mais se destacou.

$>$ O Algodão, o eucalipto, o arroz e o tremoço branco foram as culturas mais eficientes na absorção do fósforo em solo pobre neste nutriente. 


\section{ANEXOS}

Tabela 1A: Atividade específica de ${ }^{32} \mathrm{P}(\mathrm{S})$ das plantas cultivadas em solo de cerrado.

\begin{tabular}{|c|c|}
\hline Cultura & $S\left(C P M \mu g^{-1}\right)$ \\
\hline Crotalária & $150,0 \mathrm{a}$ \\
\hline Caupi & $142,6 \mathrm{a}$ \\
\hline Soja & $136,5 \mathrm{a} \mathrm{b}$ \\
\hline Stylosantes & $130,9 \mathrm{a} b$ \\
\hline Girassol & $114,4 \mathrm{a} \mathrm{b} \mathrm{c}$ \\
\hline Amendoim & $104,2 \mathrm{~b} \mathrm{c} \mathrm{d}$ \\
\hline Milheto & $104,0 \mathrm{~b} \mathrm{c} \mathrm{d}$ \\
\hline Sorgo & $100,4 \mathrm{bcde}$ \\
\hline Aveia & $92,1 \mathrm{c} \mathrm{de} \mathrm{f}$ \\
\hline Milho & $87,2 \mathrm{c} \mathrm{de} \mathrm{fg}$ \\
\hline Braquiária & $84,7 \mathrm{c} \mathrm{de} \mathrm{fgh}$ \\
\hline Feijão & $84,5 \mathrm{c} \mathrm{de} \mathrm{ggh}$ \\
\hline Trigo & $77,2 \mathrm{de} \mathrm{f} \mathrm{g} \mathrm{h} \mathrm{i}$ \\
\hline Mucuna & 66,5 e f g h i j \\
\hline Tomate & 65,5 e $f \mathrm{gh} \mathrm{i} \mathrm{j}$ \\
\hline Triticale & $57,5 \mathrm{f} \mathrm{g} \mathrm{h} \mathrm{i} \mathrm{j} \mathrm{k}$ \\
\hline Cevada & $51,0 \mathrm{~g} \mathrm{~h} \mathrm{i} \mathrm{j} \mathrm{k}$ \\
\hline Tremoço & $49,2 \mathrm{~h} \mathrm{i} \mathrm{j} \mathrm{k}$ \\
\hline Arroz & $44,2 \mathrm{i} \mathrm{j} \mathrm{k}$ \\
\hline Eucalipto & $39,2 \mathrm{j} \mathrm{k}$ \\
\hline Algodão & $35,3 \mathrm{j} \mathrm{k}$ \\
\hline Guandu & $27,8 \mathrm{k}$ \\
\hline $\mathrm{F}$ & $28,15^{*}$ \\
\hline CV (\%) & 14,13 \\
\hline Média & 83,86 \\
\hline
\end{tabular}


Tabela 2A: Atividade específica de ${ }^{32} \mathrm{P}(\mathrm{S})$ para o tremoço branco e híbridos de milho avaliados em solo de cerrado ("cultivado").

\begin{tabular}{|c|c|}
\hline Híbrido & $\mathrm{S}\left(\mathrm{CPM} \mu \mathrm{g}^{-1}\right)$ \\
\hline P30F80 & $45,63 \mathrm{a}$ \\
\hline C909 & $44,37 \mathrm{a} \mathrm{b}$ \\
\hline PX1409K & $43,85 \mathrm{a} \mathrm{b} \mathrm{c}$ \\
\hline C333B & $43,77 \mathrm{a} \mathrm{b} c$ \\
\hline P30F88 & $43,62 \mathrm{a} \mathrm{b} c$ \\
\hline P3081 & $43,55 \mathrm{a} \mathrm{b} c$ \\
\hline P3071 & $43,34 \mathrm{a} \mathrm{b} \mathrm{c} \mathrm{d}$ \\
\hline DINA766 & $41,72 \mathrm{abcde}$ \\
\hline P3041 & $41,57 \mathrm{abcde}$ \\
\hline P3021 & $41,55 \mathrm{abcde}$ \\
\hline ZN8452 & $41,42 \mathrm{abcde}$ \\
\hline AG7575 & $41,18 \mathrm{abcdef}$ \\
\hline C747 & $40,50 \mathrm{abcdef}$ \\
\hline DKB911 & $40,49 \mathrm{a} b \mathrm{cdef}$ \\
\hline AG6018 & $40,27 \mathrm{abcdef}$ \\
\hline ZN8550 & $40,14 \mathrm{abcdef}$ \\
\hline PX1379F & $39,79 a b c d e f$ \\
\hline TORK & $39,65 \mathrm{abcdef}$ \\
\hline ZN8410 & $39,26 \mathrm{abcdefg}$ \\
\hline P30K 75 & $38,69 \mathrm{bcde} \mathrm{fg}$ \\
\hline AG9090 & $38,64 \mathrm{bcde} \mathrm{fg}$ \\
\hline PX1359G & $37,42 \mathrm{c} \mathrm{de} \mathrm{fg}$ \\
\hline P3027 & $36,62 \mathrm{de} \mathrm{f} g$ \\
\hline PX1339F & 35,95 e $\mathrm{f} g$ \\
\hline P30F33 & 35,78 e $\mathrm{f} g$ \\
\hline DINA657 & 35,17 e $f \mathrm{~g}$ \\
\hline ZN8471 & 34,91 e $f \mathrm{~g}$ \\
\hline C813 & 34,81 e $\mathrm{f} g$ \\
\hline P30F45 & $34,45 \mathrm{f} \mathrm{g}$ \\
\hline ZN8420 & $32,40 \mathrm{~g}$ \\
\hline Tremoço & $13,89 \mathrm{~h}$ \\
\hline $\mathrm{F}$ & $21,56^{*}$ \\
\hline CV (\%) & 5,52 \\
\hline Média & 38,85 \\
\hline
\end{tabular}


Tabela 3A: Classificação dos híbridos de milho quanto à época de maturação.

\begin{tabular}{lc}
\hline Híbrido & Classificação \\
\hline P30F80 & Médio \\
C909 & Precoce \\
PX1409K & Precoce \\
C333B & Médio \\
P30F88 & Médio \\
P3081 & Precoce \\
P3071 & Precoce \\
DINA766 & Precoce \\
P3041 & Médio \\
P3021 & Médio \\
ZN8452 & Precoce \\
AG7575 & Precoce \\
C747 & Precoce \\
DKB911 & Precoce \\
AG6018 & Precoce \\
ZN8550 & Precoce \\
PX1379F & Precoce \\
TORK & Precoce \\
ZN8410 & Precoce \\
P30K75 & Médio \\
AG9090 & Precoce \\
PX1359G & Precoce \\
P3027 & Médio \\
PX1339F & Precoce \\
P30F33 & Precoce \\
DINA657 & Precoce \\
ZN8471 & Precoce \\
C813 & Precoce \\
P30F45 & Precoce \\
ZN8420 & Precoce \\
\hline
\end{tabular}




\section{REFERÊNCIAS BIBLIOGRÁFICAS}

ADÁMOLI, J.; MACEDO, J.; AZEVEDO, L.G.; NETTO, J.M. Caracterização da região dos cerrados. In: Goedert, W.J. ed. Solos dos cerrados; tecnologias e estratégias de manejo. Planaltina. EMBRAPA-CPAC/São Paulo: Nobel, 1986. p.3374.

ALVES, V.M.C., et al.. Efeito da omissão de fósforo na absorção de nitrogênio por híbridos de milho (Zea mays, L.). Revista Ceres, v.43, n.248, p.435-43, 1996.

ALVES, V.M.C.; NOVAIS, R.F.; OLIVEIRA, M.F.G.; SANT’ANNA, R. Cinética e translocação de fósforo em híbridos de milho. Pesquisa Agropecuária Brasileira, v.33, n.7, p.1047-52, 1998.

ANDREW, C.S.; JOHNSON, A.D.; SANDLAND, R.L. Effect of aluminium on the growth and chemical composition of some and temperate pasture legumes. Australian Journal of Agricultural Research, v.24, p.325-39, 1973.

ANGHINONI, I.; VOLKART, C.R.; FATTORE, N.; ERNANI, P.R. Morfologia de raízes e cinética da absorção de nutrientes em diversas espécies e genótipos de plantas. Revista Brasileira de Ciência do Solo, v.13, p.355-61, 1989.

BAHIA FILHO, A.F.C.; MAGNAVACA, R.; SCHAFFERT, R.E.; ALVES, V.M.C. Identification, utilization, and economic impact of maize germplasm tolerant to low levels of phosphorus and toxic levels of exchangeable aluminum in Brasilian soils. 
In: MONIZ, A.C. et al. Plant-soil interactions at low pH. Brasília: SBCS, 1997. p.59-70.

BAKER, D.E.; JARRE, A.E.; MARSHALL, L.E.; THOMAS, N.I. Phosphorus uptake from soils by corn hybrids selected for high and low phosphorus accumulation. Agronomy Journal, v.62, p.103-6, 1970.

BALIGAR, V.C.; PITTA, G.V.E.; GAMA, E.E.G.; SCHAFFERT, R.E.; BAHIA FILHO, A.F.C.; CLARK, R.B. Soil acidity effects on nutrient use efficiency in exotic maize genotypes. Plant and Soil, v.192, p.9-13, 1997.

BARROW, N.J. The response to phosphate of two annual pasture species. Australian Journal of Agricultural Research, v.26, p.145-56, 1975.

BRAUM, S.M.; HELMKE, P.A. White lupin utilizes soil phosphorus that is unavailable to soybean. Plant and Soil, v.176, p.95-100, 1995.

BULL, L.T.; CANTARELLA, H. Cultura de milho, fatores que afetam a produtividade. Potafos. 301p. 1993.

CASTELLS, A.J., et al.. Absorção de fósforo como critério de seleção de genótipos de soja quanto à tolerância ao alumínio. Pesquisa Agropecuária Brasileira, v.20, n.10, p.1163-70, out. 1985.

CHANG, S.C.; JACKSON, M.L. Fractionation of soil phosphorus. Soil Science, v.84, p.133-44, 1957.

CLARK, R.B.; BROWN, J.C. Differential mineral uptake by maize inbreds. Communications in Soil Science and Plant Analysis, v.5, p.213-27, 1974. 
COLOMB, B.; KINIRY, J.R.; DEBAEKE, P. Effect of soil phosphorus on leaf development and senescence dynamics of field-grown maize. Agronomy Journal, v.92, p.428-35, 2000.

DI, H.J.; CAMERON, K.C.; MCLAREN, R.G. Isotopic dilution methods to determine the gross transformation rates of nitrogen, phosphorus, and sulfur in soil: a review of the teory, methodologies, and limitations. Australian Journal of Soil Research, v.38, p.213-30, 2000.

EPSTEIN, E. Nutrição mineral de plantas: princípios e perspectivas. Rio de Janeiro: Livros Técnicos e Científicos, 1975, 341p.

EPSTEIN, E.; JEFFERIES, R.L. The genetic basis of selective ion transport in plants. Annual Review of Plant Physiology, v.15, p.169-84, 1964.

FÖHSE, D.; CLAASSEN, N.; JUNGK, A. Phosphorus efficiency of plants: External and internal $\mathrm{P}$ requirement and $\mathrm{P}$ uptake efficiency of different plant species. Plant and Soil, v.110, p. 101-9, 1998.

FOX, R.H. Selection for phosphorus efficiency in corn. Communications in Soil Science and Plant Analysis, v.9, n.1, p.13-37, 1978.

FOY, C.D. Toxic factors in acid soils. II. Diferencial aluminium tolerance of plant species. Soil Science Society of American Proceeding, v.28, p.27-32, 1964.

FURLANI, A.M.C.; BATAGLIA, O.C.; LIMA, M. Eficiência de linhagens de milho na absorção e utilização de fósforo em solução nutritiva. Bragantia, v.44, n.1, p.12947, 1985.

FURLANI, P.R.; CLARK, R.B. Screening sorghum for aluminium tolerance in nutrient solutions. Agronomy Journal, v.73, p.587-94, 1981. 
FURLANI, P.R.; FURLANI, A.M.C. Tolerância a alumínio e eficiência a fósforo em milho e arroz: Características independentes. Bragantia, v.50, n.2, p.331-40, 1991.

GARDNER, W.K.; BARBER, D.A.; PARBERRY, D.G. The acquisition of phosphorus by Lupinus albus L. III. The probable mechanism by which phosphorus movement in the soil/root interface is enhanced. Plant and Soil, v.70, p.107-24, 1983.

GARDNER, W.K.; PARBERRY, D.G.; BARBER, D.A. The acquisition of phosphorus by Lupinus albus L. I. Some characteristics of the soil/root interface. Plant and Soil, v.68, p.19-32, 1982a.

GARDNER, W.K.; PARBERRY, D.G.; BARBER, D.A. The acquisition of phosphorus by Lupinus albus L. II. The effect of varying phosphorus supply and soil type on some characteristics of the soil/root interface. Plant and Soil, v.68, p.33-41, 1982b.

GOEDERT, W.J.; LOBATO, E.; LOURENÇO, S. Nutrient use efficiency in brasilian acid soils: Nutrient management and plant efficiency. In: MONIZ, A.C. et al. Plant-soil interactions at low pH. Brasília: SBCS, 1997. p.97-104.

GOEDERT, W.J.; SOUZA, D.M.G.; LOBATO, E. Fósforo. In: GOEDERT, W.J. Solos dos cerrados. Tecnologias e estratégias de manejo. Ed. Nobel/EMBRAPA. p.129-66, 1985.

GRAHAM, R.D.; ASCHER, J.S.; HYNES, S.C. Selecting zinc-efficient cereal genotypes for soils low in zinc status. Plant and Soil, v. 146, p.241-50, 1992.

HERNANDEZ, R.J.M.; SILVEIRA, R.I. Efeitos da saturação por bases, relações $\mathrm{Ca}: \mathrm{Mg}$ no solo e níveis de fósforo sobre a produção de material seco e nutrição mineral do milho (Zea mays L). Scientia Agricola, v.55, n.1, p.79-85, Jan./Abr. 1998. 
HOCKING, P.J.; KEERTHISINGHE, G.; SMITH, F.W.; RANDALL, P.J. Comparation of the ability of different crop species to access poorly-available soil phosphorus. In: TANDO et al. Plant Nutrition - for sustainable food production and environment. Kluwer Academic Publishers. p.305-08, 1997.

HOFFLAND, E.; FINDENEGG, G,R,; NELEMANS, J.A. Solubilization of rock phosphate by rape. II. Local root exudation of organic acids as a response to Pstarvation. Plant and Soil, v.113, p.161-5, 1989.

KEERTHISINGHE, G.; HOCKING, P.J.; RYAN, P.R.; DELHAIZE, E. Effect of phosphorus supply on the formation and function of proteoid roots of white lupin (Lupinus albus L.). Plant, Cell and Environment, v.21, p.467-78, 1997.

KELTJENS, W.G. Plant adaptation and tolerance to acid soils; its possible Al avoidance - A review. In: MONIZ, A.C. et al. Plant-soil interactions at low pH. Brasília: SBCS, 1997. p.109-17.

LINDGREN, D.T.; GABELMAN, W.H.; GERLOFF, G.C. Variability of phosphorus uptake and translocation in Phaseolus vulgaris L. under phosphorus stress. Journal of the American Society for Horticultural Science, v.105, n.5, p.674-7, 1977.

LONERAGAN, J.F.; ASHER, C.J. Response of plants to phosphate concentration in solution culture. Soil Science. v.103, p.311-8, 1967.

LOPES, A.S. Solos sob cerrado: características, propriedades e manejo. 2. ed. Piracicaba. POTAFOS, 1984, 162p.

LUISI, M.V.V.; ROSSIELLO, R.O.P.; FERNANDES, M.S. Formas de nitrogênio e níveis de potássio sobre a absorção de fósforo por milho. Pesquisa Agropecuária Brasileira, v.18, n.4, p.343-50, 1983. 
MACEDO, J. Os solos da região dos cerrados. In: ALVAREZ, V.H.V. O solo nos grandes domínios morfoclimáticos do Brasil e o desenvolvimento sustentado. Viçosa, MG, SBCS e UFV, p.135-55, 1996.

MACHADO, C.T.T. Caracterização de genótipos de milho quanto a parâmetros morfológicos, fisiológicos e microbiológicos associados à eficiência de absorção e uso de fósforo. Rio de Janeiro, 2000. 366p. Tese (Doutorado) - Universidade Federal Rural do Rio de Janeiro.

MACHADO, C.T.T.; GUERRA, J.G.M.; ALMEIDA, D.L.; MACHADO, A.T. Variabilidade entre genótipos de milho para eficiência no uso de fósforo. Bragantia, v.58, n.1, p.109-24, 1999.

MARSCHNER, H. Mineral nutrition of higher plants. 2. ed. London: Academic Press, 1995, 889p.

MOURA, W.deM.; CASALI, V.W.D.; CRUZ, C.D.; LIMA, P.C.de. Divergência genética em linhagens de pimentão em relação à eficiência nutricional de fósforo. Pesquisa Agropecuária Brasileira, v.34, n.2, p.217-24, Fev. 1999.

NIELSEN, N.E.; BARBER, S.A. Differences among genotypes of corn in the kinetics of P uptake. Agronomy Journal, v.70, n.5, p.695-8, 1978.

NOVAIS, R.F.; SMYTH, T.J. Fósforo em solo e planta em condições tropicais. 1.ed. Viçosa: Universidade Federal de Viçosa, 1999. 399p.

OTANI, T.; AE, N.; TANAKA, M. Phosphorus uptake mechanisms of crop growth in soils with low P status. Soil Science Plant Nutrition, v.42, p.553-60, 1996.

PARENTONI, S.N.; GAMA, E.E.G.; SANTOS, M.X.; LOPES, M.A.; ALVES, V.M.C.; BAHIA FILHO, A.F.C.; VASCONCELlOS, C.A.; MAGNAVACA, R.; 
PACHECO, C.A.P.; MEIRELlES, W.F.; GUIMARÃES, P.E.O.; SILVA, A.E.; NASPOLINI FILHO, W.; MORO, J.R.; VIANA, R.T.; PITTA, G.V.E.; FRANCA, G.E.; PURCINO, A.A.C.; SOUZA, I.R.P.; ARRIEL, I.E.; MACHADO, A.T.; CORREA, L.A.; OLIVEIRA, A.C.; PAIVA, E. Adaptação de milho a solos ácidos: Tolerância à toxidez de alumínio e eficiência no uso de nutrientes no programa de pesquisa da EMBRAPA- Milho e Sorgo. In: REUNION LATINOAMERICANA DEL MAIZ, 18. Sete Lagoas, MG. Memórias... Sete Lagoas: EMBRAPACNPMS/México: CIMMYT, p.179-99, 1999.

RAIJ, B. van. Fertilidade do solo e adubação. Piracicaba: Ceres, 1991. 343p.

RAIJ, B. van; QUAGGIO, J.A.; CANTARELLA, H.; FERREIRA, M.E.; LOPES, A.S.; BATAGLiA, O.C. Análise química do solo para fins de fertilidade. Fund. Cargill, 1987, 170p.

RESENDE, M.; KER, J.C.; BAHIA FILHO, F.C. Desenvolvimento sustentado do cerrado. In: ALVAREZ, V.H.V. O solo nos grandes domínios morfoclimáticos do Brasil e o desenvolvimento sustentado. Viçosa, MG, SBCS e UFV, p.169-200, 1996.

RORISON, I.H. The response to phosphorus of some ecologically distinct plant species. I. Growth rates and phosphorus absorption. New Phytology, v.67, p.913-23, 1968.

ROSOLEM, C.A.; MARCELLO, C.S. Crescimento radicular e nutrição mineral da soja em função da calagem e adubação fosfatada. Scientia Agricola, v.55, n.3, p.448$55,1998$.

SAITO, S.M.T.; RUSCHEL, A.P. Influência da calagem, adubação fosfatada e micronutrientes na nodulação natural do feijoeiro (Phaseolus vulgaris L.). Anais da Escola Superior de Agricultura “Luiz de Queiroz”, v.35, p.545-56, 1978. 
SANTOS, J.C.P.; KAMINSKI, J.; ERNANI, P.R.; MAFRA, A.L. Rendimento de massa seca e absorção de fósforo pelo milho afetado pela aplicação de fósforo, calcário e inoculação com fungos micorrízicos. Ciência Rural, v.26, n.1, p.63-7, 1996.

SARRUGE, J.R.; HAAG, H.P. Análises químicas em plantas. Piracicaba: ESALQ, Departamento de Química, 1974, 56p.

SAWAZAKI, E.; FURLANI, P.R. Genética da tolerância ao alumínio em milho cateto. Bragantia, v.46, n.2, p.269-78, 1987.

SCHENK, M.K.; BARBER, S.A. Root characteristics of corn genotypes as related to phosphorus uptake. Agronomy Journal, v. 71, p.921-24, 1979.

SCHENK, M.K.; BARBER,S.A. Potassium and phosphorus uptake by corn genotypes grown in the field as influenced by root characteristics. Plant and soil, v.54, p. 65$76,1980$.

SCHJORRING, J.K.; NIELSEN, N.E. Root length and phosphorus uptake by four barley cultivars grown under moderate deficiency of phosphorus in field experiments. Journal of Plant Nutrition, v.10, p.1289-95, 1987.

SCOTT RUSSELL, R.; RUSSELL, E.W.; MARAIS, P.G. Factors affecting the ability of plants to absorb phosphate from soil. II. A comparison of the ability of different species to absorb labile soil phosphate. Journal of Soil Science, v.9, p.101-8, 1958.

TERUEL, D.A.; DOURADO-NETO, D.; HOPMANS, J.W.; REICHARDT, K. Alterações estruturais do sistema radicular de soja em resposta à disponibilidade de fósforo no solo. Scientia Agricola, v.58, n.1, p.55-60, Jan./Mar. 2001. 
THUNG, M. Phosphorus: A limiting nutrient in bean production in Latin America and field screening for efficiency and response. In: EL RASSAN, M. et al. Genetics aspects of plant mineral nutrition. The Netherlands, p.501-21, 1990.

VASCONCELlOS, C.A.; VIANA, M.C.M.; FERREIRA, J.J. Acúmulo de matéria seca e de nutrientes em milho cultivado no período inverno-primavera. Pesquisa Agropecuária Brasileira, v.33, n.11, p.1835-45, 1998.

VOSE, P.B. Introduction to nuclear techniques in agronomy and plant biology. Pergamon Press, 391p. 1980.

WHITEAKER, G.; GERLOFF, G.C.; GABELMAN, W.H.; LINDGREN, D. Intraspecific differences in growth of beans at stress levels of phosphorus. Journal of the American Society for Horticultural Science, v.101, p.472-5, 1976. 